\title{
TOWARD THE DEFINITION OF A NOVEL RESPONSE SPECTRUM FOR THE URBAN ENVIRONMENT
}

\author{
A. Tombari ${ }^{(1)}$, P. Cacciola ${ }^{(2)}$ \\ (1) Senior Lecturer, University of Brighton, a.tombari@brighton.ac.uk \\ (2) Reader, University of Brighton, p.cacciola@brighton.ac.uk
}

\begin{abstract}
The earthquake motion at a given point on the surface is commonly represented by elastic response spectra. Seismic codes, however, do not distinguish between ground motion in a county side or within an urban environment. The traditional elastic response spectra are a function of seismological, geological, and geotechnical parameters and they are based on the prediction of the free-field motion at the ground surface, hence, by considering the propagation of the seismic waves in the soil deposit neglecting the presence of nearby buildings. During an earthquake a vibrating structure emanates waves travelling through the ground over large distances that modifies significantly the energy of the free-field seismic waves resulting in decrements of the ground motion energy in some areas and increments in others. In the urban environment, the vibrating buildings generate the occurrence of multiple interactions that are generally referred to as seismic site-city interaction.

This paper presents a first attempt to quantify the impact of the urban environment on the commonly used elastic response spectrum defined at the free-field. A stochastic ground motion analytical model, able to capture the influence of the radiated wave field into the free field ground motion, is developed to determine novel elastic response spectra for urban areas. The proposed approach is verified through a pertinent Monte Carlo study. Moreover, a numerical model of a cluster of buildings is used to analyse the effect of the radiated waves from the ensemble of vibrating structures on the surrounding soil. Comparisons between the proposed and conventional elastic response spectra is carried out at selected locations. Remarkably, this paper shows the limitations of the traditional used elastic response spectrum that might lead to an underestimation or overestimation of the seismic response of structures in the urban environment. Therefore, the proposed approach presents a promising strategy to predict accurately the seismic response in urban areas offering potential modifications to the current seismic code prescriptions.
\end{abstract}

Keywords: Elastic response spectrum; urban environment; seismic site-city interaction; stochastic ground motion

model; 


\section{INTRODUCTION}

The engineering characterization of earthquake ground motion is a fundamental prerequisite of the current earthquake-resistant design of structures and infrastructures to ensure that, in event of earthquakes, the damages are limited and human lives are protected. International seismic codes, such as the European Eurocode 8, Italian NTC18, US ASCE 7-10, Chinese GB 50011 and Japanese BSLJ, describe the earthquake motion at a given point on the surface through the elastic response spectrum as a function of seismological, geological, and geotechnical parameters. However, during an earthquake, a vibrating building emanates waves travelling through the ground over large distances. Therefore, in the urban environment, buildings undergoing ground vibrations generate multiple interactions that are generally referred to as seismic site-city interaction (see e.g. Clouteau and Aubry, [1], Kham et al., [2], Isbililiroglu et al. [3], Wirgin [4]). The consequent ground-motion acceleration at the free-field currently used for designing civil engineering structures, therefore, can be significantly altered within an urban area. The alteration of the response spectra in urban environment, although recognized by a growing body of evidence, has not yet been included in the seismic codes likely due its complexity. However, various studies (Kennedy et al. [5], Karatzetzou and Pitilakis, [6]) pointed out the need to incorporate additional considerations such as the effect of the soilstructure interaction for a reliable seismic design.

Several methods have been used to take into account the modification of the ground motion in the urban environment in the last two-decades. Guéguen et al. [7] showed the effect of the city can be accounted for by modelling the structures as simple oscillators. Tsogka and Wirgin [8] used homogenized blocks to study the seismic response in an idealized city. Groby et al. [9] studied the seismic response of idealized $2 \mathrm{D}$ cities using a continuum viscoelastic medium. 
More recently, Cacciola and Tombari, [10] developed a novel ground motion stochastic model for the urban environment. The model recently proposed in [10] has introduced for the first time, in analytical fashion, the coupling between traditional ground motion stochastic models defined at the free field and analytical attenuation law models to consider the impact of vibrating structures on the surrounding free field ground motion.

Despite progresses have been made in the last few decades toward the refinement of stochastic models encompassing physical and/or seismological parameters (only to cite a few, see e.g. Deodatis, [11]; Spanos et al. [12]; Rezaeian and Der Kiureghian [13]; Cacciola and Deodatis [14]), there are no available tools to readily accounting for also the effect of the urban environment in the representation of the seismic action for design purposes, i.e. in the prescribed response spectrum.

In this paper, the model proposed in [10] has been first extended to take into account of i) the 3D propagation of the waves radiated by vibrating buildings in the soil medium and ii) the contribution of the higher modes to the radiated wave field. Moreover, building upon the proposed advanced ground motion model, a novel response spectrum for the urban environment is presented for the first time in this paper. The traditional free-field response spectrum is compared with the proposed urban response spectrum in presence of one or more nearby vibrating buildings. The verification of the proposed response spectrum in urban areas is carried out by pertinent Monte Carlo studies. Furthermore, in order to better appreciate the influence of vibrating buildings on the urban response spectrum acceleration, parametric analyses are undertaken considering various types of soil. Finally, a numerical case study for a cluster of buildings is also presented as an application to show the accuracy of the proposed formulation and the improvement of the prediction of the actual response spectrum against the traditional approach based on the free field model. 


\section{Problem position}

Consider the typical scenario of an incident earthquake ground motion in an urban environment. Figure 1 presents a sketch of this scenario where $U_{g}(t)$ is the ground motion in a point at the surface distant from the urban environment (i.e. the free field ground motion) and $\mathrm{U}_{\mathrm{b}}$, is the ground motion at the bedrock. Furthermore $\mathrm{U}_{\mathrm{g}}^{\mathrm{c}}(\mathrm{t})$ is also introduced to indicate the ground motion at the surface within the urban environment. It has to be emphasized under the hypothesis of homogeneous isotropic soil and for vertical propagating shear waves, the seismic codes do not make any difference between $U_{g}(t)$ and $U_{g}^{c}(t)$ irrespective of the presence of the nearby buildings. Therefore, there is no difference, according to the seismic codes and prescribed response spectra, between the ground motion at the free field and the ground motion at a point on the surface within the urban environment.

As the ground motion in the urban environment is significantly altered by the presence of the vibrating buildings (see e.g. [1]), the problem is then herein posed on how to determine the response spectrum within the urban environment starting by the knowledge of the response spectrum at the free field.

In this regard, consider first a direct approach in order to capture the influence of the urban environment on the ground motion at the surface. The dynamic response of the portion of the city shown in Figure 1, after a pertinent Finite Element discretization and assuming a linear behaviour of the system, is governed by the following equations written in terms of absolute displacements in the frequency domain: 


$$
\begin{aligned}
& {\left[\begin{array}{ccc}
\mathbf{M}_{\mathrm{u}} & 0 & 0 \\
0 & \mathbf{M}_{\mathrm{f}} & 0 \\
0 & 0 & \mathbf{M}_{\mathrm{s}}
\end{array}\right]\left[\begin{array}{c}
\ddot{\mathbf{U}}_{\mathrm{u}}(\omega) \\
\ddot{\mathbf{U}}_{\mathrm{f}}(\omega) \\
\ddot{\mathbf{U}}_{\mathrm{g}}^{\mathrm{c}}(\omega)
\end{array}\right]+\left[\begin{array}{ccc}
\widetilde{\mathbf{K}}_{\mathrm{u}}(\omega) & \widetilde{\mathbf{K}}_{\mathrm{u}, \mathrm{f}}(\omega) & 0 \\
\widetilde{\mathbf{K}}_{\mathrm{f}, \mathrm{u}}(\omega) & \widetilde{\mathbf{K}}_{\mathrm{f}}(\omega) & \widetilde{\mathbf{K}}_{\mathrm{s}, \mathrm{f}}(\omega) \\
0 & \widetilde{\mathbf{K}}_{\mathrm{f}, \mathrm{s}}(\omega) & \widetilde{\mathbf{K}}_{\mathrm{s}}(\omega)
\end{array}\right]\left[\begin{array}{c}
\mathbf{U}_{\mathrm{u}}(\omega) \\
\mathbf{U}_{\mathrm{f}}(\omega) \\
\mathbf{U}_{\mathrm{g}}^{\mathrm{c}}(\omega)
\end{array}\right]=} \\
& {\left[\begin{array}{ccc}
\widetilde{\mathbf{K}}_{\mathrm{u}}(\omega) & \widetilde{\mathbf{K}}_{\mathrm{u}, \mathrm{f}}(\omega) & 0 \\
\widetilde{\mathbf{K}}_{\mathrm{f}, \mathrm{u}}(\omega) & \widetilde{\mathbf{K}}_{\mathrm{f}}(\omega) & \widetilde{\mathbf{K}}_{\mathrm{s}, \mathrm{f}}(\omega) \\
0 & \widetilde{\mathbf{K}}_{\mathrm{f}, \mathrm{s}}(\omega) & \widetilde{\mathbf{K}}_{\mathrm{s}}(\omega)
\end{array}\right] \mathbf{T U}_{\mathrm{b}}(\omega)}
\end{aligned}
$$

where $\mathbf{M}_{\mathbf{j}}$, and $\mathbf{K}_{\mathbf{j}}(\omega)$ are the mass and the complex stiffness submatrices in which the index $\mathrm{j}=\mathrm{u}, \mathrm{f}, \mathrm{s}$ is used for indicating the buildings superstructure in the urban environment, the building foundations and the soil, respectively. Complex-valued matrices are marked by a tilde superscript. The vector $\mathbf{U}_{\mathrm{j}}$ for $\mathrm{j}=\mathrm{u}, \mathrm{f}, \mathrm{s}$ lists the displacements degrees of freedom. Note that, $\mathbf{T}$ is the frequency-independent matrix given by:

$$
\mathbf{T}=-\operatorname{Re}\{\widetilde{\mathbf{K}}(\omega)\}^{-1} \mathbf{K}_{\mathrm{b}}
$$

where $\widetilde{\mathbf{K}}(\omega)$ is the $n \times n$ complex stiffness matrix encompassing the submatrices $\mathbf{K}_{\mathrm{j}}(\omega)$ determined in Eq. (1) and $\mathbf{K}_{\mathrm{b}}$ is the stiffness matrix of the soil. Clearly, an equivalent time domain representation to encompass also soil nonlinearities can be also written in lieu of Eq. (1). The solution of Eq. (1) in principle will provide the vector $\ddot{\mathbf{U}}_{\mathrm{g}}^{\mathrm{c}}$ of the ground acceleration at a point on the surface within the urban environment for assigned ground motion at the bedrock $\mathbf{U}_{\mathrm{b}}$. The response spectrum $\operatorname{RSA}^{\mathrm{c}}(\mathrm{T})$ in the urban environment can be, therefore, determined as (see e.g. Chopra [15]):

$$
\operatorname{RSA}^{\mathrm{c}}(\mathrm{T})=\left(\frac{2 \pi}{\mathrm{T}}\right)^{2} \max _{0 \leq \mathrm{t} \leq t_{f}}|\mathrm{u}(\mathrm{T}, \mathrm{t})|
$$

where $u(T, t)$ is the response of a single degree of freedom of natural period $T=\frac{2 \pi}{\omega_{n}}\left(\right.$ with $\omega_{n}$ being the natural frequency and assigned damping ratio $\zeta$ ) to an assigned ground motion time history $\ddot{\mathrm{U}}_{\mathrm{g}}^{\mathrm{c}}$ of duration $t_{f}$. The ground motion at the bedrock can be determined by a 
deconvolution of the ground motion at the free field that in turn can be either selected from an assigned response spectrum (see, e.g. Katsanos et al. [16]) or generated through a stochastic approach (see e.g. Cacciola et al. [17]). Clearly, in this regard, Eq. (3) needs to be seen as an ensemble average of the response spectra derived by the selected or simulated free field response-spectrum-compatible ground motion time-histories.

As an alternative to this Monte Carlo approach to determine the response spectrum in the urban environment, consider the ground motion at the bedrock, $\mathbf{U}_{\mathrm{b}}$ as zero mean Gaussian stationary vector process, fully defined by the knowledge of the power spectral density matrix $\mathbf{G}_{\mathrm{ub}}(\omega)$. The stochastic characterization of the ground motion at a specific location within the urban environment can be, therefore, readily determined by pertinent elements of the response power spectral density matrix given by the following equation

$$
\mathbf{G}_{\mathbf{U}}(\omega)=\mathbf{H}(\omega) \mathbf{G}_{\mathrm{U}_{\mathrm{b}}}(\omega) \mathbf{H}^{*}(\omega)
$$

where the asterisk in Eq. (4) stands for transpose complex conjugate, and the matrix $\mathbf{H}(\omega)$ is given by

$$
\mathbf{H}(\omega)=\left(\widetilde{\mathbf{K}}(\omega)-\omega^{2} \mathbf{M}\right)^{-1} \widetilde{\mathbf{K}}(\omega) \mathbf{T}
$$

in which $\mathbf{M}$ is the $n \times n$ stiffness matrix encompassing the submatrices $\mathbf{M}_{\mathrm{j}}$ determined in Eq. (1). The pseudo-acceleration response spectrum is obtained by using the random vibration theory as the median value of the peak response of each single linear oscillator (SDOF) subjected to the Gaussian stochastic ground motion in urban areas. Therefore, the pseudoacceleration response spectrum (RSA) can be derived as follows [18]:

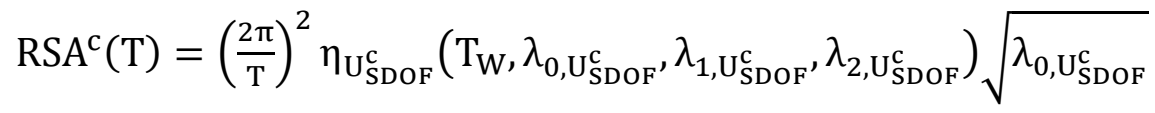


where $\mathrm{T}_{\mathrm{W}}$ is the time observing window set equal to the duration of the strong motion phase; $\lambda_{i, \mathrm{U}_{\mathrm{SDOF}}^{\mathrm{c}}}(i=0,1,2)$ are the $i$ th-order response spectral moments of the response of the SDOF system and $\eta_{\mathrm{U}_{\mathrm{SDOF}}^{\mathrm{c}}}$ is the peak factor given by

$$
\eta_{\mathrm{U}_{\mathrm{SDOF}}^{\mathrm{c}}}=\sqrt{2 \ln \left\{2 N_{\ddot{\mathrm{U}}_{\mathrm{SDOF}}^{\mathrm{c}}}\left[1-\exp \left[-\delta_{\tilde{\mathrm{U}}_{\mathrm{SDOF}}^{\mathrm{c}}}^{1.2} \sqrt{\left.\pi \ln \left(2 N_{\mathrm{U}_{\mathrm{SDOF}}^{\mathrm{c}}}^{\mathrm{c}}\right)\right]}\right]\right\}\right.}
$$

with

$$
N_{\mathrm{U}_{\mathrm{SDOF}}^{\mathrm{c}}}=\frac{T_{W}}{-2 \pi \ln 0.5} \sqrt{\frac{\lambda_{2, \mathrm{U}_{\mathrm{SDOF}}^{\mathrm{c}}}}{\lambda_{0, \mathrm{U}_{\mathrm{SDOF}}^{\mathrm{c}}}}}
$$

and

$$
\delta_{\mathrm{U}_{\mathrm{SDOF}}^{\mathrm{c}}}=\sqrt{1-\frac{\lambda_{1, \mathrm{U}_{\mathrm{SDOF}}^{\mathrm{c}}}^{2}}{\lambda_{0, \mathrm{U}_{\mathrm{SDOF}}^{\mathrm{c}} \lambda_{2, \mathrm{U}_{\mathrm{SDOF}}^{\mathrm{c}}}}}}
$$

where the response spectral moments $\lambda_{i, \mathrm{U}_{\mathrm{SDOF}}^{\mathrm{c}}}$ are given by the following equation:

$$
\lambda_{i, \mathrm{U}_{\mathrm{SDOF}}^{\mathrm{c}}}=\int_{0}^{+\infty} \omega^{i} \mathrm{G}_{\mathrm{U}_{\mathrm{SDOF}}^{\mathrm{c}}}(\omega) d \omega
$$

with $G_{U_{S D O F}^{c}}(\omega)$ power spectral density function of the response of SDOF system given by the following equation:

$$
\mathrm{G}_{\mathrm{U}_{\mathrm{SDOF}}^{\mathrm{c}}}=\left|\mathrm{H}_{\mathrm{SDOF}}(\omega)\right|^{2} \mathrm{G}_{\mathrm{Ug}_{\mathrm{g}}^{\mathrm{c}} \mathrm{U}_{\mathrm{g}}^{\mathrm{c}}}
$$

where $G_{U_{g}^{c} U_{g}^{c}}$ is the power spectral density function of the ground motion at the surface within the urban environment (given by the solution of Eq. 4) and $\mathrm{H}_{\mathrm{SDOF}}(\omega)$ is the transfer function of the SDOF system:

$$
\mathrm{H}_{\mathrm{SDOF}}(\omega)=\frac{1}{\left(1-\Omega^{2}\right)+i \eta \Omega}
$$


in which $\Omega=\omega \mathrm{T} / 2 \pi$. The stochastic approach to determine the response spectrum in the urban environment requires the solution of Eq. (6), which in turn involves the definition of the power spectral density matrix at the bedrock. The latter can be derived from the response spectrum at the free field and a pertinent deconvolution (see e.g. Cacciola et al. [19], Kramer [20]).

It has to be emphasized, that elements of the response power spectral density matrix $\mathbf{G}_{\mathbf{U}}(\omega)$ (see Eq. (4) ), and in particular the elements pertinent to the degrees of freedom of the soil at the surface, are in general function of both soil and structures within the urban environment. However, although the approach of modelling a large portion of a city might be attractive, because of the required computational demand, especially if soil (and structures) nonlinearities are considered, and for the unavoidable epistemic uncertainties involved in the model, an alternative approach is proposed in the following sections. The goal is to determine: i) the ground motion power spectral density function $G_{U_{g}^{c} U_{g}^{c}}$ at the surface within the urban environment avoiding the modelling the large portion of the city and then ii) the novel response spectrum in urban areas through a stochastic approach, through the methodology summarized in Figure 2.

\section{GROUND MOTION MODEL FOR THE URBAN ENVIRONMENT}

In order to cope with the challenging task to determine the ground motion within an urban environment, consider the influence of a single vibrating structure on the nearby free-field ground motion (Figure 3). Specifically, the aim is to determine a reliable ground motion model $\mathrm{U}_{\mathrm{g}}^{\mathrm{c}}$ able to accounting for the wave field (at a distance $\mathrm{d}$ ) radiated by the structure undergoing ground motion excitation modelled as a stochastic process $\mathrm{U}_{\mathrm{b}}$ at the bedrock. The proposed approach, originally proposed in [10] and herein extended to consider the radiated field in a 3D domain, is divided into three steps: a) the solution of dynamic response of the soil-structure 
interaction system; b) the evaluation of the radiated wave field generated by the vibrating structure and c) the evaluation of the ground motion in the proximity of a vibrating structure as a superposition of the free field ground motion and the radiated wave field. The model of Figure 3 comprises a SDOF superstructure characterized by structural stiffness, $\tilde{\mathrm{k}}_{\mathrm{str}}$, a mass at the top of the superstructure, $m_{\mathrm{str}}$, a mass at foundation level, $\mathrm{m}_{\mathrm{f}}$, and the foundation-soil system that can be fully defined by the soil-structure interaction impedance, $\tilde{\mathrm{k}}_{\mathrm{SSI}}(\omega)$. In this paper, only the horizontal absolute components of the structure and foundation displacements, $\mathrm{U}$ and $\mathrm{U}_{\mathrm{f}}$, respectively, are considered as depicted in Figure 3. The equation governing the motion of the system in terms of absolute displacements in the frequency domain reads

$$
\left(\left[\begin{array}{cc}
\tilde{\mathrm{k}}_{\mathrm{str}} & -\tilde{\mathrm{k}}_{\mathrm{str}} \\
-\tilde{\mathrm{k}}_{\mathrm{str}} & \tilde{\mathrm{k}}_{\mathrm{str}}+\tilde{\mathrm{k}}_{\mathrm{SSI}}(\omega)
\end{array}\right]-\omega^{2}\left[\begin{array}{cc}
\mathrm{m}_{\mathrm{str}} & 0 \\
0 & \mathrm{~m}_{\mathrm{f}}
\end{array}\right]\right)\left[\begin{array}{c}
\mathrm{U}(\omega) \\
\mathrm{U}_{\mathrm{f}}(\omega)
\end{array}\right]=\left[\begin{array}{c}
0 \\
\tilde{\mathrm{k}}_{\mathrm{SSI}}(\omega)
\end{array}\right] \mathrm{U}_{\mathrm{FIM}}(\omega)
$$

where $U_{\text {FIM }}(\omega)$ is foundation input motion, namely the motion of the massless foundation under seismic loading. It is noted that Eq. (13), although it has been derived directly from the lumped masses model depicted in Figure 3, it can be also obtained from Eq. (1) after a pertinent condensation of the soil degrees of freedom.

It is worth noting that the foundation input motion should include horizontal, vertical, torsional and rotational degree of freedoms; nevertheless, only the horizontal motion is considered in this work whereas the rotational modes are neglected because of the lower amounts of geometric spreading of waves from the soil-foundation interface (e.g. see Gazetas [21]).

Therefore, from Eq. (5) and Eq. (13), the solution in its expanded form is given by

$$
\left[\begin{array}{c}
\mathrm{U}(\omega) \\
\mathrm{U}_{\mathrm{f}}(\omega)
\end{array}\right]=\left(\left[\begin{array}{cc}
\tilde{\mathrm{k}}_{\mathrm{str}} & -\tilde{\mathrm{k}}_{\mathrm{str}} \\
-\tilde{\mathrm{k}}_{\mathrm{str}} & \tilde{\mathrm{k}}_{\mathrm{str}}+\tilde{\mathrm{k}}_{\mathrm{SSI}}(\omega)
\end{array}\right]-\omega^{2}\left[\begin{array}{cc}
\mathrm{m}_{\mathrm{str}} & 0 \\
0 & \mathrm{~m}_{\mathrm{f}}
\end{array}\right]\right)^{-1}\left[\begin{array}{c}
0 \\
\tilde{\mathrm{k}}_{\mathrm{SSI}}(\omega)
\end{array}\right] \mathrm{U}_{\mathrm{FIM}}(\omega)
$$


where, the complex-valued nature of the components is associated to the adoption of the hysteretic damping, $\tilde{\mathrm{k}}_{\mathrm{str}}=\mathrm{k}_{\mathrm{str}}(1+i \eta)$, where $i$ is the imaginary unit and $\eta$ is the loss factor. Therefore, the frequency transfer function of the foundation displacement, $\mathrm{H}_{\mathrm{f}}(\omega)$, defined as the ratio between the foundation displacement, $\mathrm{U}_{\mathrm{f}}(\omega)$, and the foundation input motion, $\mathrm{U}_{\mathrm{FIM}}(\omega)$, is readily derived as follows:

$$
\mathrm{H}_{\mathrm{f}}(\omega)=\frac{\mathrm{U}_{\mathrm{f}}(\omega)}{\mathrm{U}_{\mathrm{FIM}}(\omega)}=\frac{\widetilde{\omega}_{\mathrm{f}}^{2}\left(\omega^{2}-\widetilde{\omega}_{0}^{2}\right)}{\omega^{4}-\omega^{2}\left(\widetilde{\omega}_{0}^{2}+\widetilde{\omega}_{\mathrm{f}}^{2}\right)-\widetilde{\omega}_{0}^{2}\left(\beta \omega^{2}-\widetilde{\omega}_{\mathrm{f}}^{2}\right)}
$$

where

$$
\omega_{0}^{2}=\left(\frac{k_{\mathrm{str}}}{m_{\mathrm{str}}}\right)
$$

is the squared circular natural frequency of the fixed base SDOF superstructure,

$$
\omega_{\mathrm{f}}^{2}=\left(\frac{k_{\mathrm{SSI}}}{m_{\mathrm{f}}}\right)
$$

is the squared circular natural frequency of the soil-foundation system, and

$$
\beta=\left(\frac{m_{\mathrm{str}}}{m_{\mathrm{f}}}\right)
$$

is the ratio between the mass of the superstructure, $m_{\mathrm{str}}$, and the mass of its foundation, $m_{\mathrm{f}}$.

Once $U_{f}(\omega)$ is determined, the wave field radiated by the vibrating foundation needs to be determined. It is noted that the radiated wave field depends from the geometry of the foundation and different numerical strategies can be adopted (see e.g. [22-25]). Specifically, in order to account for the waves propagated by a generic shape foundation two main strategies can be pursued: i) a numerical procedure through a computational demanding Finite Element or Boundary Element analysis, or ii) an analytical approach, requiring the approximation of the generic shape foundation to an equivalent shape for which the analytical radiated wave field is 
known. The latter strategy has been undertaken in this paper in order to derive a simplified analytical formula for the urban response spectrum. The accuracy of the adopted approximation is extensively assessed literature [26] and in the following numerical applications. In this regard, the foundation of the structure, assumed shallow, is approximated by an equivalent cylindrical shape. As a consequence, the asymptotic cylindrical waves propagating from a cylinder subjected to a harmonic signal can be determined through the attenuation function given by [27]:

$$
\alpha(d, \omega)=\sqrt{\frac{B}{d}} \exp \left(-\frac{\eta_{g} \omega d}{V}\right) \exp \left[-i \omega\left(\frac{d}{v}\right)\right] \quad \forall d \geq B
$$

where $B$ is the equivalent radius of the foundation (determined either as the radius of a circle with equivalent area or distance from the centre of gravity to the border of the foundation [27]) of the equivalent oscillator, $\mathrm{d}$ is the distance between a selected point on the ground surface and the border of the foundation and $\mathrm{V}$ is the velocity of propagation of the waves through the soil having Poisson ratio, $v$, and soil loss factor, $\eta_{\mathrm{g}}$. It is noted that Eq. (19) can be further decomposed into two orthogonal components belonging to the surface ground plane, as done in Poulos, [28]. That is:

$$
\alpha(d, \omega)=\alpha_{\|}(d, \omega) \cos ^{2} \theta+\alpha_{\perp}(d, \omega) \sin ^{2} \theta \quad \forall d \geq B
$$

where $\theta$ is the angle of the line connecting source and receiver, $\alpha_{\|}$and $\alpha_{\perp}$ are the components parallel and perpendicular to the direction of propagation of the dynamic input, respectively. Approximate expressions of $\alpha_{\|}$and $\alpha_{\perp}$ can be found in Dobry and Gazetas [29], as follows

$$
\alpha_{\perp}(d, \omega)=\sqrt{\frac{B}{d}} \exp \left(-\frac{\eta_{g} \omega d}{V_{s}}\right) \exp \left[-i \omega\left(\frac{d}{v_{s}}\right)\right] \quad \forall d \geq B
$$


in which $\mathrm{V}_{\mathrm{S}}=\sqrt{G / \rho}$ is the shear wave velocity of the soil with shear modulus $G$ and mass density $\rho$, and

$$
\alpha_{\|}(d, \omega)=\sqrt{\frac{B}{d}} \exp \left(-\frac{\eta_{g} \omega d}{V_{L a}}\right) \exp \left[-i \omega\left(\frac{d}{V_{L a}}\right)\right] \quad \forall d \geq B
$$

where $\mathrm{V}_{\mathrm{La}}=\left(3.4 \mathrm{~V}_{\mathrm{s}}\right) /[\pi(1-v)]$ is the Lysmer's analogue velocity. Therefore, the wave field radiated by the vibrating foundation is given by

$$
\mathrm{U}_{\mathrm{g}}^{\mathrm{f}}(\mathrm{d}, \omega)=\alpha(\mathrm{d}, \omega) \mathrm{U}_{\mathrm{f}}^{\mathrm{r}}(\omega)=\sqrt{\frac{\mathrm{B}}{\mathrm{d}}} \exp \left(-\frac{\eta \omega \mathrm{d}}{\mathrm{V}_{\mathrm{La}}}\right) \exp \left[-\mathrm{i} \omega\left(\frac{\mathrm{d}}{\mathrm{V}_{\mathrm{La}}}\right)\right] \mathrm{U}_{\mathrm{f}}^{\mathrm{r}}(\omega) \quad \forall \mathrm{d} \geq \mathrm{a}
$$

where $U_{f}^{r}(\omega)=U_{f}(\omega)-U_{F I M}(\omega)$. Finally, the ground motion $U_{g}^{c}(d, \omega)$, at a point on the surface at a certain distance $d$ from the vibrating structure is determined as a superposition of the two effects, namely: the free field motion, $U_{g}(\omega)$, and the radiated motion $U_{g}^{f}(d, \omega)$, that is

$$
U_{g}^{c}(d, \omega)=U_{g}(\omega)+U_{g}^{f}(d, \omega)
$$

or equivalently:

$$
\mathrm{U}_{\mathrm{g}}^{\mathrm{c}}(\mathrm{d}, \omega)=\mathrm{U}_{\mathrm{g}}(\omega)+\alpha(\mathrm{d}, \omega)\left(\mathrm{U}_{\mathrm{f}}(\omega)-\mathrm{U}_{\mathrm{FIM}}(\omega)\right)
$$

Eqs (24-25) represent the ground motion in proximity of a vibrating structure at the soil surface and require the knowledge of the free field ground motion (in absence of buildings) and the foundation response. Note that, the foundation input motion, $U_{\mathrm{FIM}}(\omega)$ for normalized frequencies, $\frac{\omega \mathrm{B}}{\mathrm{V}_{\mathrm{s}}}<0.2 \sim 0.25$ or for footing foundations (see e.g., [30-33]), can be approximated by the free field motion, $\mathrm{U}_{\mathrm{g}}(\omega)$, i.e. $\mathrm{U}_{\mathrm{FIM}}(\omega) \cong \mathrm{U}_{\mathrm{g}}(\omega)$. 
Assuming that $U_{g}$ is a realization of as a stationary Gaussian random process, the pertinent ground motion acceleration power spectral density function can be determined by applying basic Random Vibration theory (see e.g. $[10 ; 34])$ in the following closed form:

$$
G_{U_{g}^{c} U_{g}^{c}}(d, \omega)=\left|1+\alpha(d, \omega) H_{f}^{r}(\omega)\right|^{2} G_{\ddot{U}_{g}}(\omega)
$$

where $\mathrm{H}_{\mathrm{f}}^{\mathrm{r}}(\omega)$ is the transfer function of the foundation in relative displacement, defined as $\mathrm{H}_{\mathrm{f}}^{\mathrm{r}}(\omega)=\mathrm{H}_{\mathrm{f}}(\omega)-1$ and $\mathrm{G}_{\ddot{U}_{\mathrm{g}}}(\omega)$ is the ground motion acceleration power spectral density function at the free field. Therefore, the pseudo-acceleration response spectrum in proximity of a vibrating structure, $\operatorname{RSA}^{\mathrm{c}}(\mathrm{T})$, is obtained through Eqs. (6-11) by using the power spectral density function derived in Eq. (26).

Moreover, in order to take into account the contribution of multiple vibrating structures on the surface, Eq. (26) can be extended by exploiting the linearity of the problem as showed in [10]. Specifically, consider the case depicted in Figure 4, in which two buildings, are represented along with the relevant degrees of freedom. Following Poulos's assumption [28-29] only the interaction of one source and one receiver at a time is considered. Therefore, the interaction between two building foundations is neglected. This assumption leads directly to the following representation of the ground motion process at a selected point within the urban environment (see Eqs. 23 and 25), in which the power spectral density function of the ground motion in the urban environment in a selected point altered by the presence of $n$ structures assumes the following form [10]

$$
\mathrm{G}_{\ddot{U}_{\mathrm{g}}^{\mathrm{c}} \ddot{U}_{\mathrm{g}}^{\mathrm{g}}}(\omega)=\left|1+\sum_{i=1}^{\mathrm{n}} \alpha_{\mathrm{i}}\left(d_{i}, \omega\right) \mathrm{H}_{\mathrm{f}}^{\mathrm{r}, \mathrm{i}}(\omega)\right|^{2} \mathrm{G}_{\ddot{U}_{\mathrm{g}} \ddot{U}_{\mathrm{g}}}(\omega)
$$

where $\alpha_{i}\left(d_{i}, \omega\right)$ is the attenuation function radiated by the $i$ th structure at a distance $d_{i}$ between its foundation and the selected point, and $\mathrm{H}_{\mathrm{f}}^{\mathrm{r}, \mathrm{i}}(\omega)$ is transfer function in terms of relative displacements 


$$
H_{f}^{r, i}(\omega)=H_{f}^{i}(\omega)-1
$$

in which $\mathrm{H}_{\mathrm{f}}^{i}(\omega)$ is the foundation transfer function of the $i$ th vibrating structure.

Clearly the $n$ structures to be included into the model defined by Eq. (33) are only those nearby the selected point. The preliminary study of the attenuation functions $\alpha_{\mathrm{i}}\left(d_{i}, \omega\right)$ will determine the size of the problem. Eq. (27) can be used along with Eqs. $(6-11)$ to determine the response spectrum at the surface in the urban environment.

\section{DERIVATION OF LATERAL-ONLY FOUNDATION}

\section{IMPEDANCES}

The 1-DOF foundation-soil system used for the derivation of the frequency transfer function of the foundation displacement, $\mathrm{H}_{\mathrm{f}}(\omega)$, given in Eq. (15) is fully defined by the lateral soilstructure interaction impedance, $\mathrm{k}_{\mathrm{SSI}}(\omega)$. However, the antisymmetric modes of oscillations such as the horizontal translation and rocking of a foundation (Gazetas, [21]) are coupled and should be represented by a 2-DOF system characterized by the horizontal impedance, $\mathrm{k}_{\mathrm{h}}(\omega)$,

the rocking impedance, $\mathrm{k}_{\mathrm{r}}(\omega)$, as well as the cross horizontal-rotational impedance, $\mathrm{k}_{\mathrm{hr}}(\omega)$. Although the foundation rotation generally generates lower amounts of geometric spreading (e.g. see Gazetas [21]) it might significantly alter the structural fundamental frequency especially for tower-like structures. In this section, a coefficient, $\chi(\omega)$, is derived in order to obtain an equivalent horizontal impedance, $\mathrm{k}_{\mathrm{SSI}}(\omega)=\chi(\omega) \mathrm{k}_{\mathrm{h}}(\omega)$, which aims to match the natural frequency of the 1-DOF foundation-soil system with the complete 2-DOF system. Let us consider a rigid foundation of mass, $m_{\mathrm{f}}$, and semi-width B, laying a soil deposit of depth $H_{\mathrm{s}}$ as depicted in Figure 5a. By considering the 2-DOF mechanical model of Figure 5b, the eigenvalue problem can be described by the following equation: 


$$
\left(\left[\begin{array}{cc}
\mathrm{k}_{\mathrm{h}}(\omega) & \mathrm{k}_{\mathrm{hr}}(\omega) \\
\mathrm{k}_{\mathrm{hr}}(\omega) & \mathrm{k}_{\mathrm{r}}(\omega)
\end{array}\right]-\omega_{j}^{2}\left[\begin{array}{cc}
\mathrm{m}_{\mathrm{f}} & 0 \\
0 & \mathrm{I}_{\mathrm{f}}
\end{array}\right]\right) \boldsymbol{\phi}_{j}=\left[\begin{array}{l}
0 \\
0
\end{array}\right]
$$

where $\omega_{j}^{2}$ is the eigenvalue of the $j$ th-mode, $\boldsymbol{\phi}_{j}$.

The impedance functions, $\mathrm{k}_{\mathrm{h}}(\omega), \mathrm{k}_{\mathrm{hr}}(\omega)$, and $\mathrm{k}_{\mathrm{hr}}(\omega)$ can be obtained through several analytical and numerical methods; just to cite a few: Beredugo and Novak [35], proposed a method to compute the impedances for embedded foundations with lateral backfill, Pais and Kausel [36], calculated approximate formulas for the dynamic stiffness of circular and rectangular foundation, and Gazetas [37] provided formulas and charts for the impedances of surface and embedded foundation of arbitrary shape.

From Eq. (29), the two undamped natural frequencies of the soil-foundation system are found as follows:

$$
\omega_{1,2}^{2}=\omega_{\mathrm{h}}^{2}\left(1+\frac{\omega_{\mathrm{r}}^{2}}{\omega_{\mathrm{h}}^{2}}\right) \frac{1}{2} \pm \frac{1}{2} \sqrt{\left(\frac{\omega_{\mathrm{r}}^{2}}{\omega_{\mathrm{h}}^{2}}-1\right)^{2}+4 \frac{\omega_{\mathrm{hr}}^{2}}{\omega_{\mathrm{h}}^{2}} \frac{\mathrm{k}_{\mathrm{hr}}}{\mathrm{k}_{\mathrm{h}}}}
$$

in which $\omega_{\mathrm{h}}=\sqrt{\left(\frac{k_{\mathrm{h}}}{m_{\mathrm{f}}}\right)}, \omega_{\mathrm{r}}=\sqrt{\left(\frac{k_{\mathrm{r}}}{m_{\mathrm{f}}}\right)}$, and $\omega_{\mathrm{hr}}=\sqrt{\left(\frac{k_{\mathrm{hr}}}{I_{\mathrm{f}}}\right)}$; it is worth noting that the dependence of the variables on $\omega$ is omitted. Since the impedance functions, $\mathrm{k}_{\mathrm{h}}(\omega), \mathrm{k}_{\mathrm{hr}}(\omega)$, and $\mathrm{k}_{\mathrm{hr}}(\omega)$, vary with the frequency $\omega$, solutions of Eq. (30) at the frequencies $\omega=\omega_{1,2}$, can be obtained through an iterative procedure. Alternatively, an approximate solution can be obtained by fixing the frequency $\omega$ at a specific value: e.g. Whitman and Richart [38] suggested a low frequency $\omega \approx 0$ for the stiffness values and an average value of the damping over the range of frequencies in which the resonance occurs. In this paper, the impedance values are calculated at the natural frequency of the soil-foundation-structure system, $\omega_{\text {SSI }}$; it is worth mentioning that this value can be obtained through an iterative procedure or from experimental modal testing of the structure of interest. 
In order to derive the equivalent natural frequency of the 1-DOF foundation system, $\omega_{\mathrm{f}}$, of Figure 5c, defined in Eq. (17) and used for the proposed stochastic ground motion model for urban environment, a reduction coefficient, $\chi(\omega)$, is derived from Eq. (28) by equating $\omega_{f} \equiv$ $\omega_{1}$ when $\omega_{\mathrm{h}}<\omega_{\mathrm{f}}$, as common for shallow foundations, or $\omega_{f} \equiv \omega_{2}$ for $\omega_{\mathrm{h}}>\omega_{\mathrm{f}}$.

$$
\chi=\frac{\omega_{1,2}^{2}}{\omega_{f}^{2}}= \begin{cases}\left(1+a_{1}\right) \frac{1}{2}-\frac{1}{2} \sqrt{\left(a_{1}-1\right)^{2}+4 a_{2}}, & \omega_{\mathrm{h}}<\omega_{\mathrm{f}} \\ \left(1+a_{1}\right) \frac{1}{2}+\frac{1}{2} \sqrt{\left(a_{1}-1\right)^{2}+4 a_{2}}, & \omega_{\mathrm{h}}>\omega_{\mathrm{f}}\end{cases}
$$

where $a_{1}=\frac{\mathrm{k}_{\mathrm{r}}}{\mathrm{k}_{\mathrm{h}}} \frac{\mathrm{m}_{\mathrm{f}}}{\mathrm{I}}$ and $a_{2}=\left(\frac{\mathrm{k}_{\mathrm{hr}}}{\mathrm{k}_{\mathrm{h}}}\right)^{2} \frac{\mathrm{m}_{\mathrm{f}}}{\mathrm{I}}$. Therefore, $\chi$ is the factor to apply to the horizontal impedance, $\widetilde{\mathrm{k}}_{\mathrm{h}}(\omega)$, in order to derive the equivalent lateral impedance, $\mathrm{k}_{\mathrm{SSI}}(\omega)=\chi(\omega) \mathrm{k}_{\mathrm{h}}(\omega)$, used for the 1-DOF foundation system.

For example, let us consider a rigid rectangular foundation of equivalent radius B, fully embedded in a uniform soil, the expressions for $a_{1}$ and $a_{2}$ are reported in Table 1 adopting the approximate parameters proposed by Beredugo and Novak [35]. It is worth noting that by adopting these approximate expressions, the coefficient of Eq. (31) is a function only of the relative embedment $\delta=\frac{e}{\mathrm{~B}}$ and the soil Poisson's coefficient, $v$; it is independent, therefore, of other important properties in soil-structure interaction such as shear wave velocity, soil density and foundation unit weight.

Figure 6a shows the variation of the reduction factor for a rectangular foundation of equivalent radius, $\mathrm{B}$, with the relative embedment for soils characterized by shear wave velocity $V_{S}$ in the range $[100-800] \mathrm{m} / \mathrm{s}$ and Poisson's coefficient, $v=0.3$, considering the approximate and the exact expressions of Eq. (29). It can be seen that the approximate curve is independent from the shear wave velocity of the soil. Figure $6 \mathrm{~b}$ shows the excellent accuracy of the proposed approximate reduction coefficient compared to the exact one. Note that, furthermore, the 
natural frequency of the soil foundation system is decreasing with the increase of the relative embedment $\delta$, due to the consequent increment of the foundation mass.

\section{CONTRIBUTION OF STRUCTURAL HIGHER-MODES}

In an urban environment, the approximation of the building through SDOF systems (capturing in essence their first fundamental mode in the ground motion direction) might be not sufficiently accurate. The contribution of higher modes might be needed to capture the multiple interactions (see e.g. Vicencio and Alexander [39]). In this regard, let $\mathrm{m}_{i}$ the number of relevant modes of the $i$ th structure $(i=1 \ldots n)$ considered as fixed base. Although the classical modal analysis is not rigorous on soil-structure interaction problems, (see e.g. [40-41]), an approximate strategy to consider the contribution of higher modes is given by the superposition of the effects that each equivalent modal oscillator produces in the radiated wave field. The power spectral density function of the ground motion of Eq. (27) in the selected point $k$ on the soil surface is, therefore, expanded as

$$
\mathrm{G}_{\ddot{\mathrm{U}}_{\mathrm{g}}^{\mathrm{c}} \ddot{\mathrm{U}}_{\mathrm{g}}^{\mathrm{g}}}(\omega)=\left|1+\sum_{i=1}^{n} \sum_{\mathrm{j}=1}^{\mathrm{m}_{i}} \alpha_{i}\left(\mathrm{~d}_{i}, \omega\right) \mathrm{H}_{\mathrm{f}, i}^{\mathrm{r}, \mathrm{j}}(\omega)\right|^{2} \mathrm{G}_{\ddot{U}_{\mathrm{g}} \ddot{\mathrm{U}}_{\mathrm{g}}}(\omega)
$$

where $\alpha_{i}\left(\mathrm{~d}_{i}, \omega\right) \mathrm{H}_{\mathrm{f}, i}^{\mathrm{r}, \mathrm{j}}(\omega)$ is the contribution of the transfer function $\mathrm{H}_{\mathrm{f}, i}^{\mathrm{r}, \mathrm{j}}(\omega)$ of the $j$ th-natural mode of the $i$ th-structure defined by the corresponding participating masses of the fixed base structure and soil-foundation system through the coefficient $\beta$ of Eq. (18).

\section{DIRECT DERIVATION OF APPROXIMATED ELASTIC}

\section{RESPONSE SPECTRUM FOR URBAN ENVIRONMENT}

In this section an approximate direct evaluation of the pseudo-acceleration response spectrum for urban environment is also derived. In this regard, by exploiting the selectivity of the filter 
$\mathrm{H}_{\mathrm{SDOF}}(\omega)$ in Eq. (12), the zeroth order spectral moment can be approximated as (see e.g. Vanmarke [18]) as

$$
\lambda_{0, \mathrm{U}_{\mathrm{SDOF}}^{\mathrm{c}}} \cong \frac{\pi \mathrm{G}_{\ddot{\mathrm{U}} \mathrm{g} \ddot{\mathrm{g}} \mathrm{c}}^{\mathrm{c}}\left(\omega_{n}\right)}{4 \zeta \omega_{n}^{3}}
$$

Therefore Eq. (6) can be rewritten as

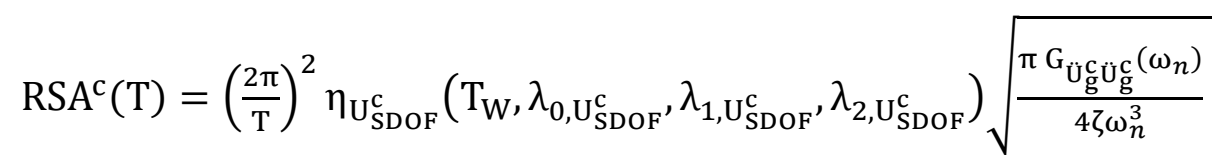

Furthermore, substituting the proposed expressions of the power spectral density function for the ground motion in the urban environment (see e.g. Eqs. 26-28) in Eq. (32) after simple algebra and considering $\eta_{U_{S D O F}^{c}}^{c} \cong \eta_{U_{S D O F}}$ the approximate response spectrum for the urban environment can be written for a single nearby structures:

$$
\operatorname{RSA}^{\mathrm{c}}(\mathrm{T})=\left|1+\alpha\left(\mathrm{d}, \frac{2 \pi}{\mathrm{T}}\right) \mathrm{H}_{\mathrm{f}}^{\mathrm{r}}\left(\frac{2 \pi}{\mathrm{T}}\right)\right| \operatorname{RSA}(\mathrm{T}) ; \quad \operatorname{RSA}^{\mathrm{c}}(\mathrm{T})>\operatorname{RSA}(\mathrm{T})
$$

and for the most general case of multiple structures considering also the contribution of higher modes:

$$
\operatorname{RSA}^{\mathrm{c}}(\mathrm{T})=\left|1+\sum_{i=1}^{n} \sum_{\mathrm{j}=1}^{\mathrm{m}_{i}} \alpha_{i}\left(\mathrm{~d}_{i}, \frac{2 \pi}{\mathrm{T}}\right) \mathrm{H}_{\mathrm{f}, i}^{\mathrm{r}, \mathrm{j}}(\omega)\right| \operatorname{RSA}(\mathrm{T}) ; \quad \operatorname{RSA}^{\mathrm{c}}(\mathrm{T})>\operatorname{RSA}(\mathrm{T})
$$

The approximate formulas in Eqs. (34-35) provide a direct strategy for assessing the effect of the urban environment on the free field motion considering parameters of easy evaluation: structural factors such as $\omega_{0}, \omega_{\mathrm{f}}$ and the mass ratio, $\beta$, which can be obtained via either structural identification or approximate formulations; soil parameters such as shear wave velocity, $\mathrm{V}_{\mathrm{s}}$, soil Poisson coefficient, $v$, and soil loss factor, $\eta$; and geometrical dimensions such as the equivalent radius of the foundation, $B$, distance, $d$, and angle, $\theta$, respect to the 
considered location to be analyzed. It has to be emphasized that ground motion acceleration within the urban environment can be also reduced respect to the free field case, however although the approximate formulas might also be able to estimate those reductions, they need to be seen as a strategy to quickly evaluate the detrimental influence of nearby structures on the free field response spectrum to be followed by detailed specific studies. Therefore, the approximate response spectra given by Eqs. (37-38) need to be seen valid for $\operatorname{RSA}^{\mathrm{c}}(\mathrm{T})>$ RSA(T) only.

\section{NUMERICAL RESULTS}

\subsection{Parametric Analysis}

In this section, the proposed methodology to determine the modification of the response spectrum in proximity of a vibrating structure is applied by considering the ground types A, B, $\mathrm{C}$, and D according to EN1998-1. A parametric analysis by varying the mass ratio $\beta$ in the range $0.1-10$ and $\gamma\left(=\right.$ ratio $\left.\omega_{\mathrm{f}} / \omega_{0}\right)$ between $0.1-3$, is conducted.

Figure 7 shows the maximum and minimum deviations from the EN1998 response spectrum, RSA, induced by a vibrating building with fundamental period $\mathrm{T}_{0}=0.2 \mathrm{~s}$ calculated through the proposed methodology of Eq. (6) as $\mathrm{RSA}^{\mathrm{c}} / \mathrm{RSA}$ at a distance, $\mathrm{d}=10 \mathrm{~m}$, from its equivalent radius, $B=3 \mathrm{~m}$. It is worth noting that deviations up to $\pm 90 \%$ are observed regardless the ground types. These deviations are higher when the ratio $\omega_{\mathrm{f}} / \omega_{0}$ is between $0.1-0.5$ with the maximum and minimum values occurring at different ratios as a function as the ground types. Moreover, the maximum and minimum deviations are also depending on the mass ratio $\beta$, with massive structures having a larger effect on a wider range of $\gamma$. 
The ratio $\operatorname{RSA}^{\mathrm{c}}(\mathrm{T}) / \mathrm{RSA}(\mathrm{T})$ is also depicted in Figure 8a-b-c showing the deviation of the response spectrum altered by a vibrating structure compared to the EN1998 response spectrum for ground type $\mathrm{D}$, for three structural fundamental periods of $\mathrm{T}_{0}=0.2 \mathrm{~s}, 0.5 \mathrm{~s}$, and $1 \mathrm{~s}$, respectively. The maximum deviation, up to about $60 \%$, occurs at a period $T$ which increases with the increase of the fundamental structural period, $\mathrm{T}_{0}$, and effects of the vibrating structure on the response spectrum are greatly dependent upon the ratio $\omega_{\mathrm{f}} / \omega_{0}$.

Finally, the case of a single-degree-of-freedom structure with natural frequency of $\omega_{0}$ equal to $31.42 \mathrm{rad} / \mathrm{s}\left(\mathrm{T}_{0}=0.2 \mathrm{~s}\right)$ and mass ratio $\beta=1.83$, has been selected for the parametric analysis on the influence of the distance, $d$, on the response spectrum. The soil-foundation impedance functions for a strip foundation with semi-width of $3 \mathrm{~m}$ are reported in Figure 9 for the four different ground types. The frequency of the soil-foundation system, $\omega_{\mathrm{f}}$, is calculated from Eq. (17), by considering the constant values of the soil-foundation impedances demarked by a solid circle in Figure 9 which are evaluated at the natural frequency of the structure-soil-foundation system, $\omega_{\text {SSI }}$. Pertinent data used to derive the response spectrum through the proposed methodology are reported in Table 2.

The response spectra are calculated through the proposed stochastic model for four soil types, i.e. A (Figure 10a), B (Figure 11a), C (Figure 12a), and D (Figure 13a), according to EN19981, for several distances. The traditional response spectrum for free field motion is indicated by a grey shade. It can be observed that the ground motion nearby the vibrating building differs from the traditional response spectrum manifesting zones with higher and lower spectral acceleration. Remarkably, the influence of vibrating structure for the selected set of structural parameters significantly increases the value of the response spectrum at certain periods. Specifically, Figure 10b, Figure 11b, Figure 12b, and Figure 13b show the proposed response spectrum at a distance equal to $10 \mathrm{~m}$ from the vibrating building for the four soil types A-B-C- 
$\mathrm{D}$, respectively. It is worth noting that a peak of the spectral acceleration is achieved around the fundamental period of the vibrating building considering soil-structure interaction effects with natural circular frequency, $\omega_{\mathrm{SSI}}$, as reported in Table 2; therefore, the peak shifts towards longer periods with the decrease of the shear wave velocities of the soil. Moreover, significant effects caused by the propagation of the waves generated by the vibrating building through the soil, are detected at distances of $\mathrm{d}=20 \mathrm{~m}$ as reported in Figure $10 \mathrm{c}$ Figure 11c, Figure 12c, and Figure $13 \mathrm{c}$ or even longer (i.e. beyond $100 \mathrm{~m}$ ) depending from the soil type.

\subsection{COMPARISON OF THE PROPOSED ANALYTICAL MODEL WITH MCS}

In this section, the proposed response spectrum model in the proximity of a single vibrating structure is compared with the results obtained by applying the Monte Carlo Simulation of the pertinent finite element model depicted in Figure 14. The geotechnical and structural data used to characterize the model are reported in Table 2 for ground types A, B, C, and D according to EN1998-1. The finite element soil domain is 50m-deep and 800m-wide in order to minimize the reflections of the waves on the lateral free boundaries of the domain. The soil domain is modelled with 4-Node Quadrilateral Elements under plane strain conditions. A constant modal damping equal to 0.05 is considered for both soil and structure, corresponding at the hysteretic damping with loss factor of 0.1 at the fundamental periods of the model. The seismic excitation is applied at the bedrock of the soil deposit. Monte Carlo simulation is performed by considering 100 Gaussian stationary ground motion time histories generated in order to be spectrum-compatible (Cacciola [42]) at the ground surface with the relevant design spectrum proposed by EN1998-1 for each type of soil considered in this analysis. The average response spectrum acceleration for urban environment $\left(\operatorname{RSA}^{\mathrm{c}}(\mathrm{T})\right)$, is obtained at two locations of the surface, i.e. point A $(d=10 \mathrm{~m})$ and B $(d=20 \mathrm{~m})$ and compared with the proposed response spectrum in Figure 15 and in Figure 16, respectively. It can be observed a good matching between the proposed $\operatorname{RSA}^{\mathrm{c}}(\mathrm{T})$, indicated by a black continuous curve with the average 
response spectrum derived from the MCS, shown as a dashed black curve, especially around the natural frequency of the nearby structure. Therefore, despite the approximation of the strip foundation to a cylindrical shape the results from the analytical model provide an excellent matching with those from FE model. As observed in the previous parametric analysis, the response spectrum in the proximity of a vibrating building is largely different from the response spectrum defined in the seismic codes, such as EN1998-1 represented by the continuous blue curve. Moreover, on the same Figure 15 and in Figure 16, the average response spectra of the free field motion, calculated at large distance $(\mathrm{d}=380 \mathrm{~m})$, are depicted; although a large FEM domain is adopted, still minor reflections are visible, especially when the structural response is significant as occurs in the case of ground type B and C.

\subsection{APPLICATION TO A CLUSTER OF BUILDINGS}

In this section the proposed response spectrum model is applied to a selected case study: the pavilion A of the Messina Polyclinic, Italy. A numerical finite element model is created using original drawings and technical reports. The cluster of buildings founded on a 30m-depth deposit which elastic properties are reported in Table 3 is shown in Figure 17a. The soil deposit is characterised by shear wave velocity $\mathrm{V}_{\mathrm{S}, 30}=180 \mathrm{~m} / \mathrm{s}$ in agreement with available public data and, thus is classified as ground soil C from EN1998-1. The cluster of buildings comprises 6 main reinforced concrete frame structures, as depicted in Figure 17b. Relevant parameters, used to assess the frequency transfer function of the foundation displacement of Eq. (15), are reported in Table 4. It is worth noting that in order to consider an equivalent SDOF, the first pertinent modal frequency in the direction of the seismic input (assumed acting in the $\mathrm{Y}$ direction) for each structure is considered in order to derive $\omega_{0}$; it is noted equivalent formulations as a function of the building height as proposed by EN1998-1 could also be used in practical applications. It is noted that for simplicity's sake the soil-structure interaction impedance, $\tilde{\mathrm{k}}_{\mathrm{SSI}}(\omega)$, which real and imaginary parts are shown in Figure 18a-b for each set of 
foundations, is substituted by a single value scalar value $\tilde{\mathrm{k}}_{\mathrm{SSI}}\left(\omega_{\mathrm{SSI}}\right)$, i.e calculated for the soilfoundation-structure system frequency $\omega_{\mathrm{SSI}}$, and reported in Table 4 . Therefore, in order to assess the effect of the cluster of buildings on the surrounding free field, the proposed model of Eq. (33) is applied. Three locations illustrated in Figure 17b are considered to highlight different contribution of the cluster; positional data are reported in Table 5 and Table 6. Figure 19a-c-e shows the power spectral density $G_{\ddot{U} \ddot{g}^{c} \ddot{U}_{g}^{c}}$ functions of the urban environment for the four considered positions compared to the spectrum compatible power spectral density functions of the free field motion, $G_{\ddot{U}_{g}} \ddot{U}_{g}$ for a seismic loading applied to the $Y$ direction. It can be seen that the cluster of buildings strongly affects the free field motion by altering the seismic energy, generating zones either with higher or lower energy content. A verification of the results is carried out by performing a Monte Carlo study with 50 simulated ground motions generated in order to be compatible with ground type $\mathrm{C}$ response spectrum at the ground surface; each ground motion is then deconvoluted to be applied at the rigid bedrock. The results in terms of averaged power spectral density functions are also plotted in Figure 19a-ce. It is worth noting that the proposed power spectral density function for urban environment given by Eq. (26) match reasonably well the results of the Monte Carlo Simulation; peaks that are not accounted by the proposed model are related to the higher modes of the buildings.

Moreover, the response spectra for the three considered locations are also derived in Figure 19b-d-f. The proposed response spectrum obtained through the power spectral density function of Eq. (33) is compared to the response spectrum according to EN1998-1. Note that there are clearly identifiable zones with higher $(+15 \%)$ and lower peak $(-42 \%)$ response than the traditional free-field response spectrum, manifesting the underestimation or overestimation of the seismic forces determined by using the current response spectra. The proposed response spectrum is well in agreement with the average response spectrum obtained from the Monte Carlo Simulation analysis, indicated by a dashed curve; the mismatch occurs at one peak 
induced by the $2^{\text {nd }}$ modes of vibration of the cluster of buildings as verified by the results of the modal analysis. In the same Figure 19, the response spectrum envelope determined through Eq. (38) is depicted; this tool can be used for a quick assessment of the impact of the urban environment on the ground motion before proceeding with a more complex analysis (for instance, by solving Eq. 33). Finally, in Figure 20 the proposed response spectrum is obtained by adding up the contribution of the $2^{\text {nd }}$ modes by using Eq. (34); it is worth noting that low period peaks are captured showing zones with $36 \%$ spectral acceleration higher than what prescribed on the seismic code. The largest peak visible in Figure $20 \mathrm{a}-\mathrm{b}$ is due to the $2^{\text {nd }}$-modal shape of the nearest buildings B1 and B2, which are similar in dynamics characteristics (see Table 4), whereas the same peak is reduced at the point P3 (Figure 20c) where adjacent buildings have different natural frequencies. Moreover, the approximate response spectrum envelopes obtained through Eq. (38) showed a fair matching with the proposed response spectrum of Eq. (34). The proposed response spectrum, therefore, might provide a valuable strategy to identify whether the urban environment might amplify the prescribed free field response spectrum in order to proceed with further more complex numerical simulations

\section{CONCLUding REMARKS}

This paper presents a first attempt to study the modification of traditional elastic response spectra due to the influence of the urban environment. A stochastic ground motion analytical model, derived by a simplified discrete model able to capture the influence of the radiated wave field into the free field ground motion, has been used to determine the novel elastic response spectrum for urban areas. The proposed methodology to determine the urban response spectrum has been validated through a pertinent Monte Carlo study on a reliable finite element model. 
Remarkably, the free field motion described through the traditional elastic response spectrum is strongly affected by the urban environment with deviations up to $\pm 80-90 \%$ at short distances of about $10 \mathrm{~m}$ and still noticeable at longer distances of about $100 \mathrm{~m}$, for the analysed cases.

The impact of vibrating buildings on the free field motion is higher when the soil-structure interaction effect is relevant, that is for massive structures and compliant soil-foundation systems.

A case study, the pavilion A of the Messina Polyclinic, Italy, has been also investigated. This represents a cluster of 6 MDOFs buildings. The proposed elastic response spectra, calculated at several locations, show spectral acceleration 36\% higher than what prescribed on the seismic code.

Therefore, this paper has pointed out limitations of the traditional used elastic response spectrum that might lead to an underestimation of the seismic response of structures in the urban environment. It is worth pointing out that the study of wave reflections and refractions in a heterogeneous multiphase random non-linear medium is still an open challenging problem that can be addressed only through specific advanced numerical analyses. Several assumptions in line with the state of the art of the study of structure-soil-structure interaction and site-city interaction have been made in this paper to derive a simplified method to determine the proposed urban response spectrum. The accuracy of those approximations and assumption are documented in related literature and might be released if detailed soil investigations are performed. It has to be emphasized that the amplification due to the nearby vibrating structure need to be seen as a starting point for design applications (neglected up to now by any seismic code). Practitioners who might need accurately estimate the amplification induced in the urban environment need to conduct more detailed numerical analyses using experimental data on soil and nearby structures. It is also worth noting that the proposed model is applied to analyse the 
alteration of the horizontal response spectra due to vibrating structures. The approach can be also adopted to study of the modification of the vertical response herein not considered for simplicity's sake. In conclusion, as manifested by the numerical study, the proposed approach presents a reliable strategy to predict accurately the seismic response in urban areas offering potential modifications to the current seismic code prescriptions.

\section{REFERENCES}

[1]D. Clouteau and D. Aubry, 'Modifications of the Ground Motion in Dense Urban Areas', Journal of Computational Acoustics, vol. 09, no. 04, pp. 1659-1675, Dec. 2001, doi: 10.1142/S0218396X01001509.

[2]M. Kham, J.-F. Semblat, P.-Y. Bard, and P. Dangla, 'Seismic Site-City Interaction: Main Governing Phenomena through Simplified Numerical Models', Bulletin of the Seismological Society of America, vol. 96, no. 5, pp. 1934-1951, Oct. 2006, doi: 10.1785/0120050143.

[3]Y. Isbiliroglu, R. Taborda, and J. Bielak, 'Coupled Soil-Structure Interaction Effects of Building Clusters during Earthquakes', Earthquake Spectra, vol. 31, no. 1, pp. 463-500, Feb. 2015, doi: 10.1193/102412EQS315M.

[4]A. Wirgin, 'Earthquakes in cities revisited', arXiv:1607.08856 [physics], Jul. 2016, Accessed: Jun. 17, 2019. [Online]. Available: http://arxiv.org/abs/1607.08856.

[5]R. P. Kennedy, R. H. Kincaid, and S. A. Short, 'Engineering characterization of ground motion Task II Effects of ground motion characteristics on structural response considering localized structural nonlinearities and soil-structure interaction effects Volume 2', NTIS, United States, NUREG/CR--3805-Vol2, 1985. 
[6]A. Karatzetzou and D. Pitilakis, 'Modification of Dynamic Foundation Response Due to Soil-Structure Interaction', Journal of Earthquake Engineering, vol. 22, no. 5, pp. 861-880, May 2018, doi: 10.1080/13632469.2016.1264335.

[7]P. Guéguen, P.-Y. Bard, and F. Chavez-Garcia, 'Site-City Interaction in Mexico City-Like environments: An Analytical Study', Bulletin of the Seismological Society of America, vol. 92, no. 2, pp. 794-811, 2002.

[8]C. Tsogka and A. Wirgin, 'Simulation of seismic response in an idealized city', Soil Dynamics and Earthquake Engineering, vol. 23, no. 5, pp. 391-402, Jul. 2003, doi: 10.1016/S0267-7261(03)00017-4.

[9]J. Groby, C. Tsogka, and A. Wirgin, 'Simulation of seismic response in a city-like environment', Soil Dynamics and Earthquake Engineering, vol. 25, no. 7-10, pp. 487-504, Aug. 2005, doi: 10.1016/j.soildyn.2004.11.007.

[10]P. Cacciola and A. Tombari, 'A stochastic ground motion model for the urban environment', Probabilistic Engineering Mechanics, vol. 59, p. 103026, Jan. 2020, doi: 10.1016/j.probengmech.2020.103026.

[11]G. Deodatis, 'Non-stationary stochastic vector processes: seismic ground motion applications', Probabilistic Engineering Mechanics, vol. 11, no. 3, pp. 149-167, Jul. 1996, doi: $10.1016 / 0266-8920(96) 00007-0$.

[12]P. D. Spanos, A. Giaralis, and N. P. Politis, 'Time-frequency representation of earthquake accelerograms and inelastic structural response records using the adaptive chirplet decomposition and empirical mode decomposition', Soil Dynamics and Earthquake Engineering, vol. 27, no. 7, pp. 675-689, Jul. 2007, doi: 10.1016/j.soildyn.2006.11.007. 
[13]S. Rezaeian and A. Der Kiureghian, 'Simulation of synthetic ground motions for specified earthquake and site characteristics', Earthquake Engineering \& Structural Dynamics, p. n/an/a, 2010, doi: 10.1002/eqe.997.

[14]P. Cacciola and G. Deodatis, 'A method for generating fully non-stationary and spectrumcompatible ground motion vector processes', Soil Dynamics and Earthquake Engineering, vol. 31, no. 3, pp. 351-360, Mar. 2011, doi: 10.1016/j.soildyn.2010.09.003.

[15]A. K. Chopra, Dynamics of structures: theory and applications to earthquake engineering, Fifth edition. Hoboken, NJ: Pearson, 2017.

[16]E. I. Katsanos, A. G. Sextos, and G. D. Manolis, 'Selection of earthquake ground motion records: A state-of-the-art review from a structural engineering perspective', Soil Dynamics and Earthquake Engineering, vol. 30, no. 4, pp. 157-169, Apr. 2010, doi: 10.1016/j.soildyn.2009.10.005.

[17]P. Cacciola, L. D'Amico, and I. Zentner, 'New insights in the analysis of the structural response to response-spectrum-compatible accelerograms', Engineering Structures, vol. 78, pp. 3-16, Nov. 2014, doi: 10.1016/j.engstruct.2014.07.015.

[18] E.H. Vanmarcke, D.A. Gasparini Simulated earthquake ground motions. In: Proceedings of the 4th international conference on smirt, K1/9, San Francisco; 1977.

[19]P. Cacciola, P. Colajanni, and G. Muscolino, 'Combination of Modal Responses Consistent with Seismic Input Representation', Journal of Structural Engineering, vol. 130, no. 1, pp. 47-55, Jan. 2004, doi: 10.1061/(ASCE)0733-9445(2004)130:1(47).

[20]S. L. Kramer, Geotechnical earthquake engineering. Upper Saddle River, N.J.: Prentice Hall, 1996. 
[21]G. Gazetas, 'Analysis of machine foundation vibrations: State of the art', International Journal of Soil Dynamics and Earthquake Engineering, vol. 2, no. 1, pp. 2-42, Jan. 1983, doi: 10.1016/0261-7277(83)90025-6.

[22]Y. Hisada, ‘An efficient method for computing Green's functions for a layered half-space with sources and receivers at close depths', Bulletin of the Seismological Society of America, vol. 84, no. 5, pp. 1456-1472, Oct. 1994.

[23]Y. Hisada, 'An efficient method for computing Green's functions for a layered half-space with sources and receivers at close depths (part 2)', Bulletin of the Seismological Society of America, vol. 85, no. 4, pp. 1080-1093, Aug. 1995.

[24]W. S. Hall and G. Oliveto, Eds., Boundary element methods for soil-structure interaction. Dordrecht, The Netherlands ; Boston: Kluwer Academic Publishers, 2003.

[25]E. Kausel, Fundamental Solutions in Elastodynamics: A Compendium. Cambridge: Cambridge University Press, 2006.

[26] J. W. Meek and J. P. Wolf, 'Approximate Green's Function for Surface Foundations', Journal of Geotechnical Engineering, vol. 119, no. 10, pp. 1499-1514, Oct. 1993, doi: 10.1061/(ASCE)0733-9410(1993)119:10(1499).

[27]P. M. Morse and K. U. Ingard, Theoretical acoustics. Princeton, N.J: Princeton University Press, 1986.

[28]H. G. Poulos, 'Behavior of Laterally Loaded Piles: I-Single Piles', Journal of the Soil Mechanics and Foundations Division, ASCE, vol. 97, no. 5, pp. 711-731, 1971.

[29]R. Dobry and G. Gazetas, 'Simple method for dynamic stiffness and damping of floating pile groups', Geotechnique, London, vol. 38, no. 4, pp. 557 - 574, 1988. 
[30]P. C. Jennings and J. Bielak, 'Dynamics of building-soil interaction', Bulletin of the Seismological Society of America, vol. 63, no. 1, pp. 9-48, Feb. 1973.

[31]J. Bielak, 'Dynamic behaviour of structures with embedded foundations', Earthquake Engineering \& Structural Dynamics, vol. 3, no. 3, pp. 259-274, 1974, doi: 10.1002/eqe.4290030305.

[32]J. P. Wolf, Dynamic soil-structure interaction. Englewood Cliffs, N.J.: Prentice-Hall, 1985.

[33]S. Carbonari, M. Morici, F. Dezi, and G. Leoni, 'A lumped parameter model for timedomain inertial soil-structure interaction analysis of structures on pile foundations', Earthquake Engineering \& Structural Dynamics, vol. 47, no. 11, pp. 2147-2171, Sep. 2018, doi: 10.1002/eqe.3060.

[34]J. B. Roberts and P. D. Spanos, Random vibration and statistical linearization. Mineola, NY: Dover Publications, 2003.

[35]Y. O. Beredugo and M. Novak, 'Coupled Horizontal and Rocking Vibration of Embedded Footings', Can. Geotech. J., vol. 9, no. 4, pp. 477-497, Nov. 1972, doi: 10.1139/t72-046.

[36]A. Pais and E. Kausel, 'Approximate formulas for dynamic stiffnesses of rigid foundations', Soil Dynamics and Earthquake Engineering, vol. 7, no. 4, pp. 213-227, Oct. 1988, doi: 10.1016/S0267-7261(88)80005-8.

[37]G. Gazetas, 'Formulas and Charts for Impedances of Surface and Embedded Foundations', Journal of Geotechnical Engineering, vol. 117, no. 9, pp. 1363-1381, Sep. 1991, doi: 10.1061/(ASCE)0733-9410(1991)117:9(1363).

[38]R. V. Whitman and F. E. Richart, 'Design Procedures for Dynamically Loaded Foundations', Journal of the Soil Mechanics and Foundations Division, vol. 93, no. 6, pp. 169193, 1967. 
[39]F. Vicencio and N. A. Alexander, 'Higher mode seismic structure-soil-structure interaction between adjacent building during earthquakes', Engineering Structures, vol. 174, pp. 322-337, Nov. 2018, doi: 10.1016/j.engstruct.2018.07.049.

[40]J. M. Roesset, R. V. Whitman, and R. Dobry, 'Modal Analysis for Structures with Foundation Interaction', Journal of the Structural Division, vol. 99, no. 3, pp. 399-416, 1973.

[41]J. Enrique Luco and A. Lanzi, 'Approximate soil-structure interaction analysis by a perturbation approach: The case of stiff soils', Soil Dynamics and Earthquake Engineering, vol. 51, pp. 97-110, Aug. 2013, doi: 10.1016/j.soildyn.2013.04.005.

[42]P. Cacciola, 'A stochastic approach for generating spectrum compatible fully nonstationary earthquakes', Computers \& Structures, vol. 88, no. 15-16, pp. 889-901, Aug. 2010, doi: 10.1016/j.compstruc.2010.04.009. 

Table 1 Approximate expressions for $\mathrm{a}_{1}$ and $\mathrm{a}_{2}$ by adopting parameter from Beredugo and Novak, [34].

$v$

0

$\frac{3.6 \delta^{3}+12.9 \delta^{2}+30 \delta+30}{\left(\delta^{2}+4\right)(3.6 \delta+4.3)^{2}}$

0.3

$\frac{4.02 \delta^{3}+14.34 \delta^{2}+30 \delta+30}{\left(\delta^{2}+4\right)(4.02 \delta+4.78)}$

0.5 $a_{2}$

$$
\begin{aligned}
& \frac{5547 \delta^{2}}{\left(\delta^{2}+4\right)(36 \delta+43)^{2}} \\
& \frac{171363 \delta^{2}}{\left(\delta^{2}+4\right)(201 \delta+239)^{2}} \\
& \frac{7803 \delta^{2}}{\left(\delta^{2}+4\right)(41 \delta+51)^{2}}
\end{aligned}
$$


Table 2 Parameters used to characterize the response spectrum for ground type $A-B-C-D$

\begin{tabular}{|c|c|c|c|c|c|c|c|c|}
\hline Ground & $V_{S}$ & $\omega_{0}$ & $\beta$ & $\omega_{\mathrm{f}} / \omega_{0}$ & $\omega_{\text {SSI }}$ & $\eta$ & $\mathrm{k}_{\mathrm{h}} / \mathrm{k}_{\mathrm{st}}$ & $\chi$ \\
\hline Туре & {$[\mathrm{m} / \mathrm{s}]$} & {$[\mathrm{rad} / \mathrm{s}]$} & & & {$[\mathrm{rad} / \mathrm{s}]$} & & & \\
\hline A & 800 & 31.42 & 1.83 & 3.13 & 28.55 & 0.15 & 1.19 & 0.93 \\
\hline B & 400 & 31.42 & 1.83 & 1.24 & 19.56 & 0.16 & 0.85 & 0.93 \\
\hline $\mathrm{C}$ & 200 & 31.42 & 1.83 & 0.58 & 10.53 & 0.16 & 0.76 & 0.93 \\
\hline D & 100 & 31.42 & 1.83 & 0.28 & 5.3715 & 0.15 & 0.73 & 0.93 \\
\hline
\end{tabular}


Table 3 Elastic soil properties to characterize the site response analysis

$\begin{array}{llllll}\text { Layer } 1 & \text { Layer } 2 & \text { Layer } 3 & \text { Layer } 4 & \text { Layer } 5 & \text { Layer } 6\end{array}$

$\begin{array}{ccccccc}\text { Depth }[\mathrm{m}] & 0-5 & 6-10 & 11-15 & 16-20 & 21-25 & 26-30 \\ \mathrm{~V}_{\mathrm{S}}[\mathrm{m} / \mathrm{s}] & 70 & 110 & 248 & 386 & 524 & 662 \\ \mathrm{E}_{\mathrm{SI}}[\mathrm{MPa}] & 24.7 & 60.96 & 309.8 & 750.6 & 1383.2 & 2207.7 \\ \rho\left[\mathrm{kg} / \mathrm{m}^{3}\right] & 1937.5 & 1937.5 & 1937.5 & 1937.5 & 1937.5 & 1937.5\end{array}$


Table 4 Main data used to define the ground motion model for the cluster of buildings

$\begin{array}{llllll}\text { B1 } & \text { B2 } & \text { B3 } & \text { B4 } & \text { B5 } & \text { B6 }\end{array}$

\begin{tabular}{|c|c|c|c|c|c|c|}
\hline$\omega_{0}[\mathrm{rad} / \mathrm{s}]$ & 11.81 & 11.32 & 13.95 & 13.95 & 16.96 & 11.32 \\
\hline$\omega_{\mathrm{f}}[\mathrm{rad} / \mathrm{s}]$ & 147 & 91.90 & 85.00 & 93.00 & 85.00 & 91.90 \\
\hline $\mathrm{k}_{\mathrm{SSI}}$ & $1.1921 \mathrm{e}+06$ & $1.1921 \mathrm{e}+06$ & $1.0431 \mathrm{e}+06$ & $0.8033 \mathrm{e}+06$ & $1.0431 \mathrm{e}+06$ & $0.9686 \mathrm{e}+06$ \\
\hline \multicolumn{7}{|l|}{$[\mathrm{kN} / \mathrm{m}]$} \\
\hline$\eta$ & 0.1 & 0.1 & 0.2 & 0.16 & 0.38 & 0.1 \\
\hline$\beta$ & 32.7 & 31.7 & 26.1 & 38.7 & 14.7 & 32.8 \\
\hline $\mathrm{r}[\mathrm{m}]$ & 7 & 7.5 & 7 & 6.5 & 6.5 & 7.5 \\
\hline
\end{tabular}


Table 5 Distances of each building from the considered locations.

$\begin{array}{lcccccc}\mathrm{S}[\mathrm{m}] & \text { B1 } & \text { B2 } & \text { B3 } & \text { B4 } & \text { B5 } & \text { B6 } \\ \text { P1 } & 15.6 & 14 & 28 & 28 & 60 & 52 \\ \text { P2 } & 65 & 20 & 68 & 33 & 88 & 54 \\ \text { P3 } & 56 & 55 & 34 & 24 & 19 & 14\end{array}$


Table 6 Slope of the line connecting each building from the considered locations expressed as angle

\begin{tabular}{lcccccc}
$\theta\left[^{\circ}\right]$ & B1 & B2 & B3 & B4 & B5 & B6 \\
\cline { 2 - 6 } P1 & 180 & 0 & 122 & 270 & 106 & 75 \\
P2 & 180 & 180 & 159 & 130 & 140 & 112 \\
P3 & 196 & 285 & 250 & 270 & 180 & 0
\end{tabular}




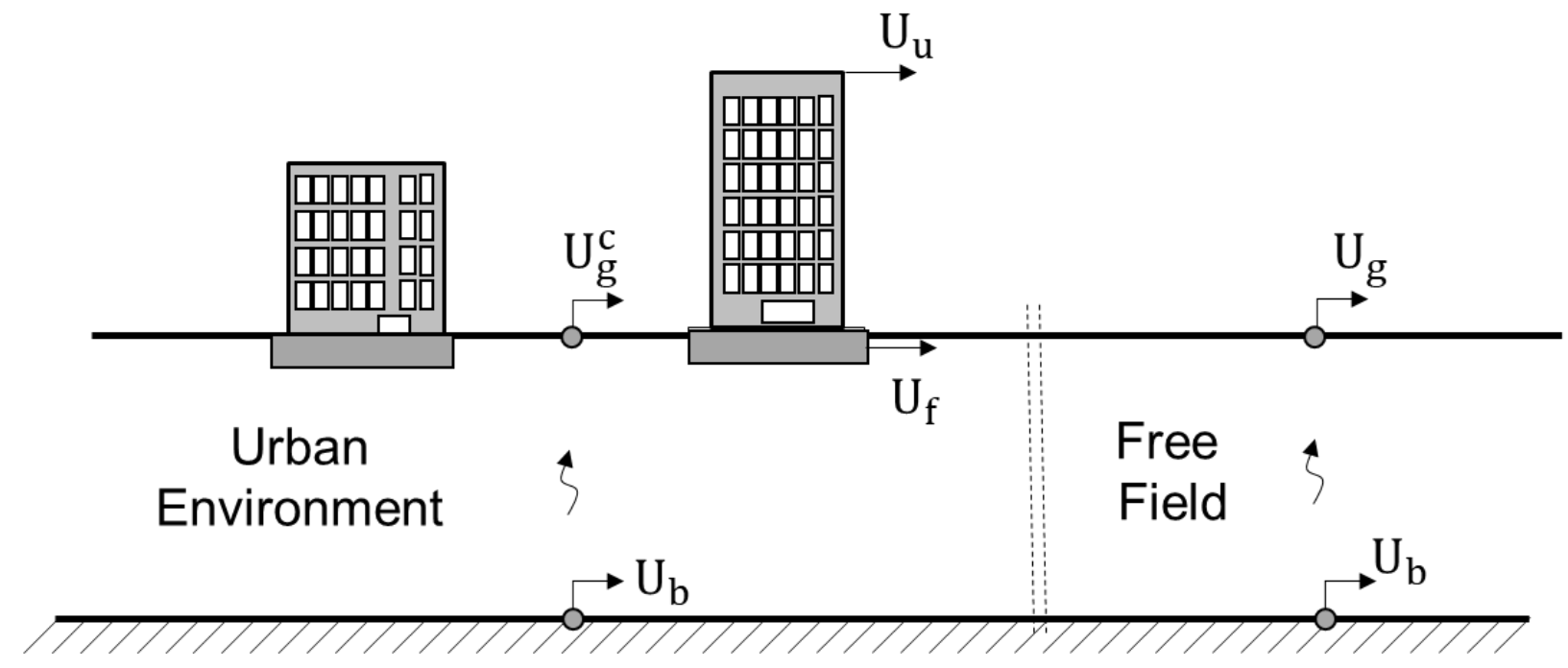

Figure 1 Seismic response of the surface ground motion in urban environment 


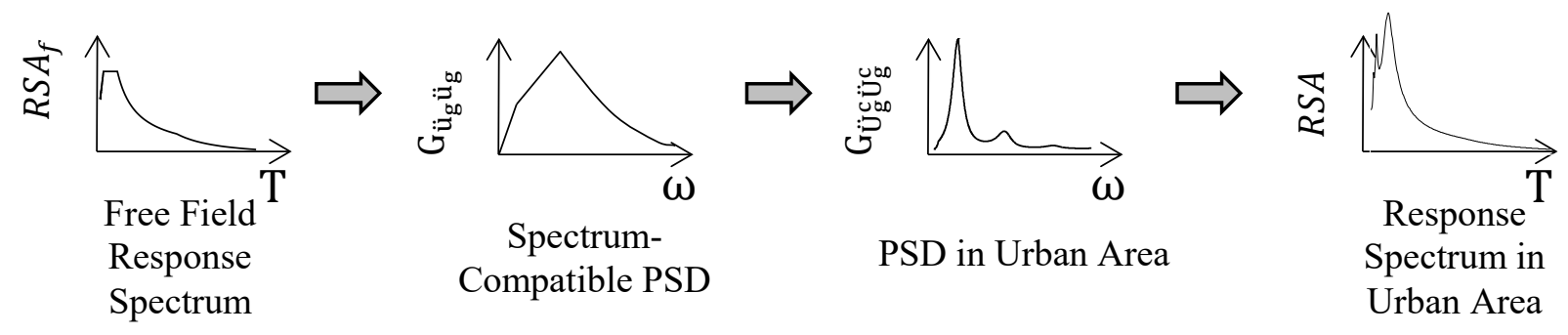

Figure 2 Proposed stochastic methodology to derive novel definition of response spectrum in urban areas. 


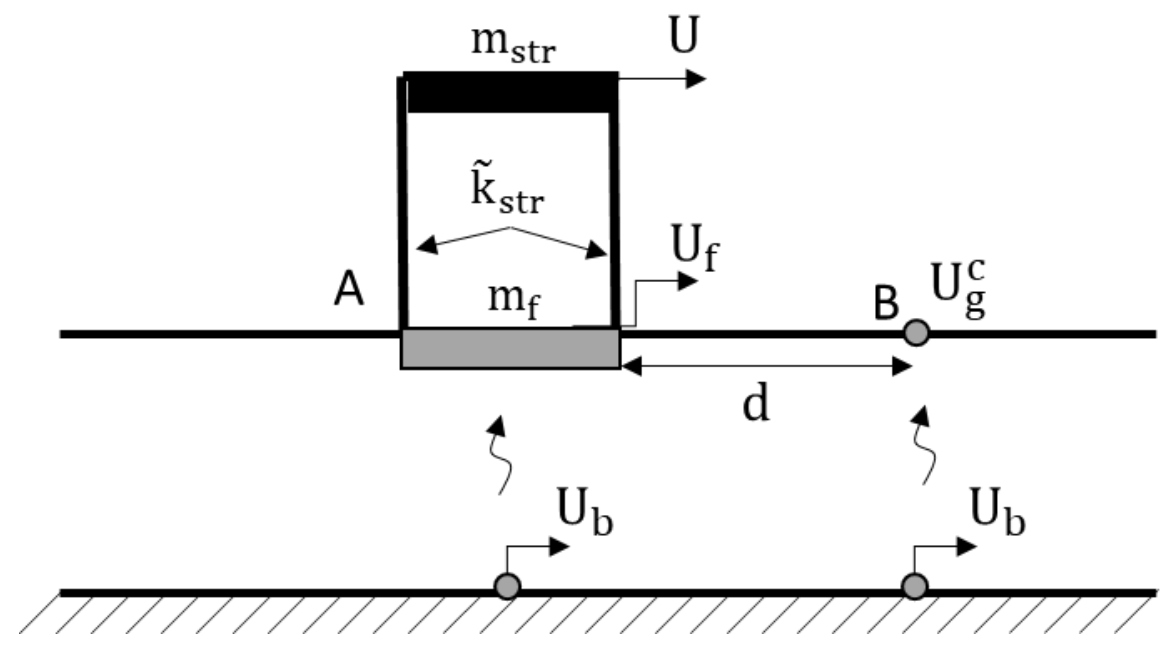

Figure 3 Seismic wave field surrounding a building induced by bedrock excitation 


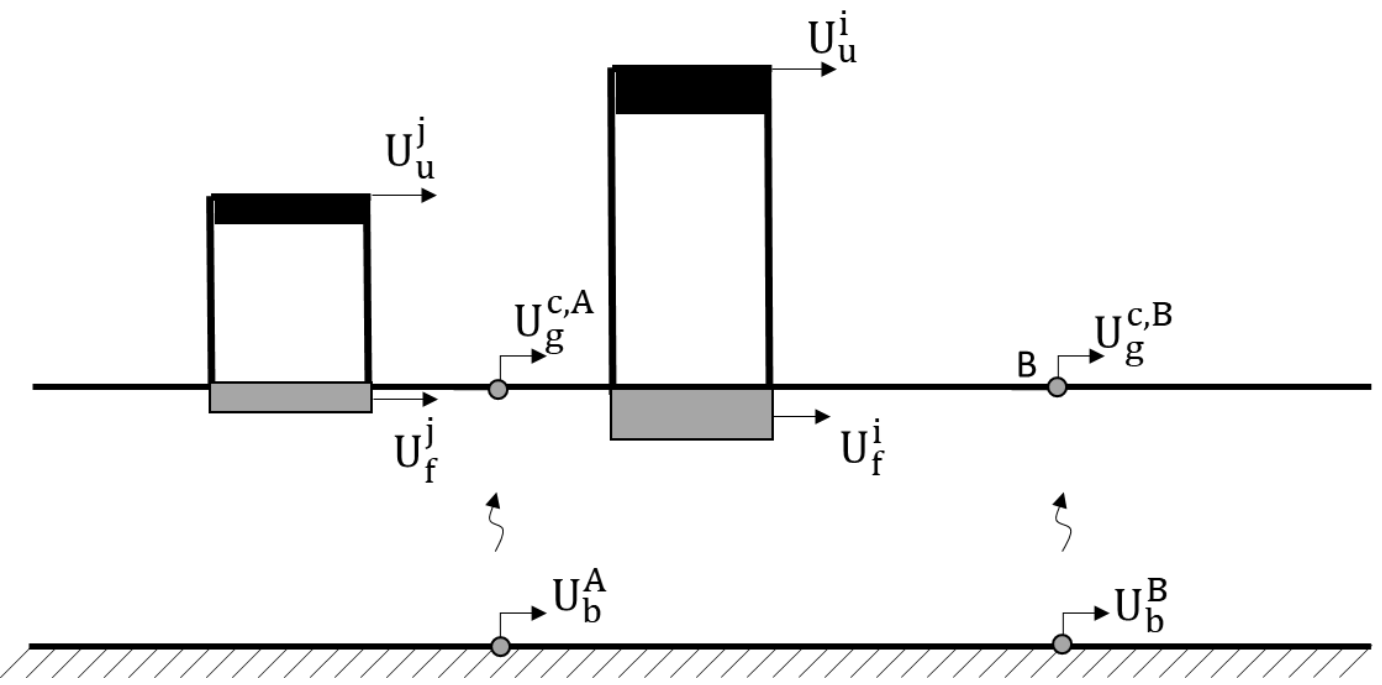

Figure 4 Seismic wave field surrounding a cluster of buildings induced by coherent or incoherent bedrock excitation 


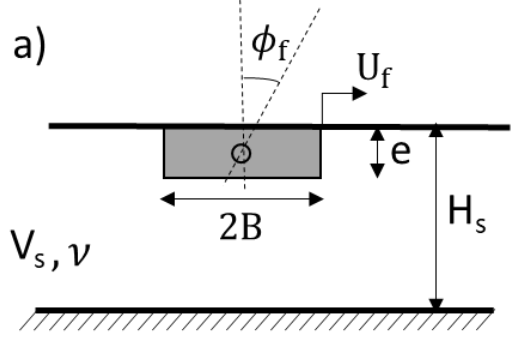

b)

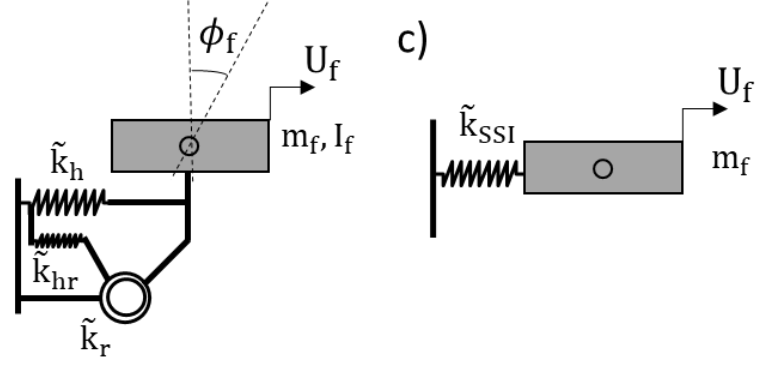

Figure 5 Soil-foundation system a) continuous model, b) 2-DOF and, c) 1-DOF discrete model 


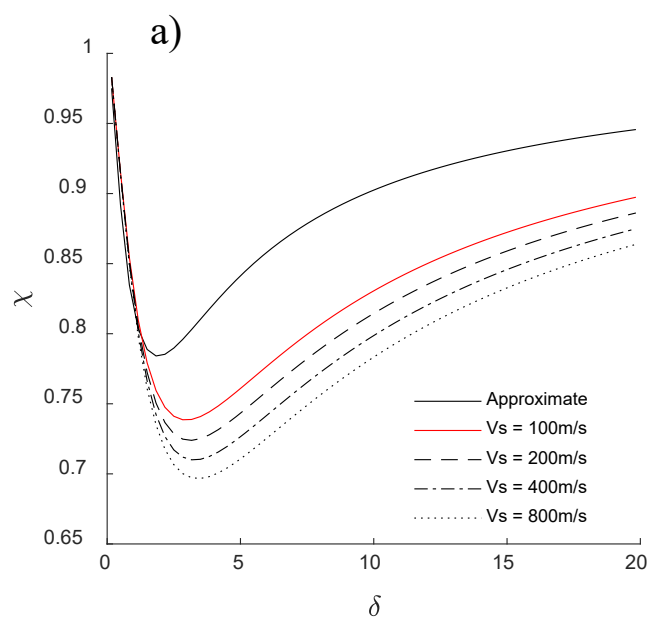

b)

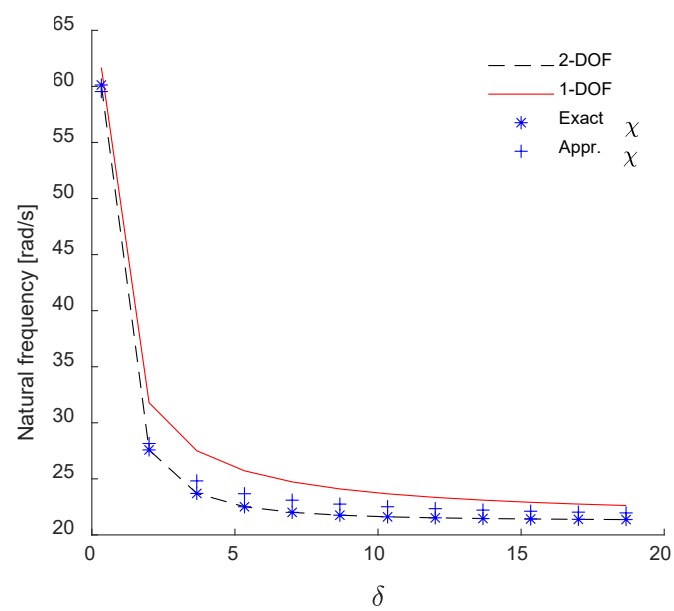

Figure 6 a) Approximate and exact expressions for the coefficient $\chi$ and b) natural frequency variation of the soil-foundation system with the relative embedment . 

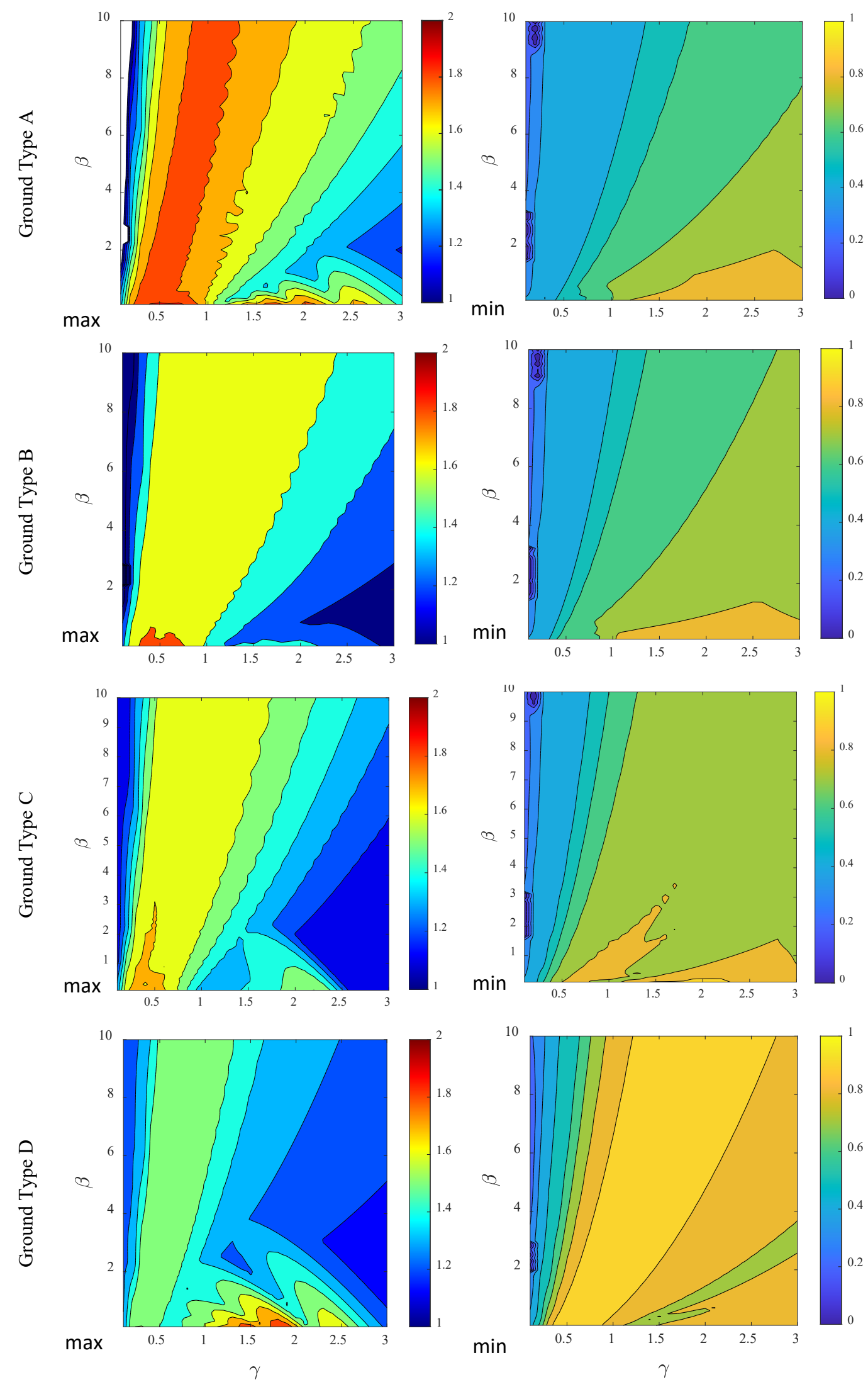

Figure 7 Maximum and minimum deviation from the EN1998 response spectrum in acceleration induced by a structure with $\mathrm{T}_{0}=0.2 \mathrm{~s}$ at a distance $\mathrm{d}=10 \mathrm{~m}$. 

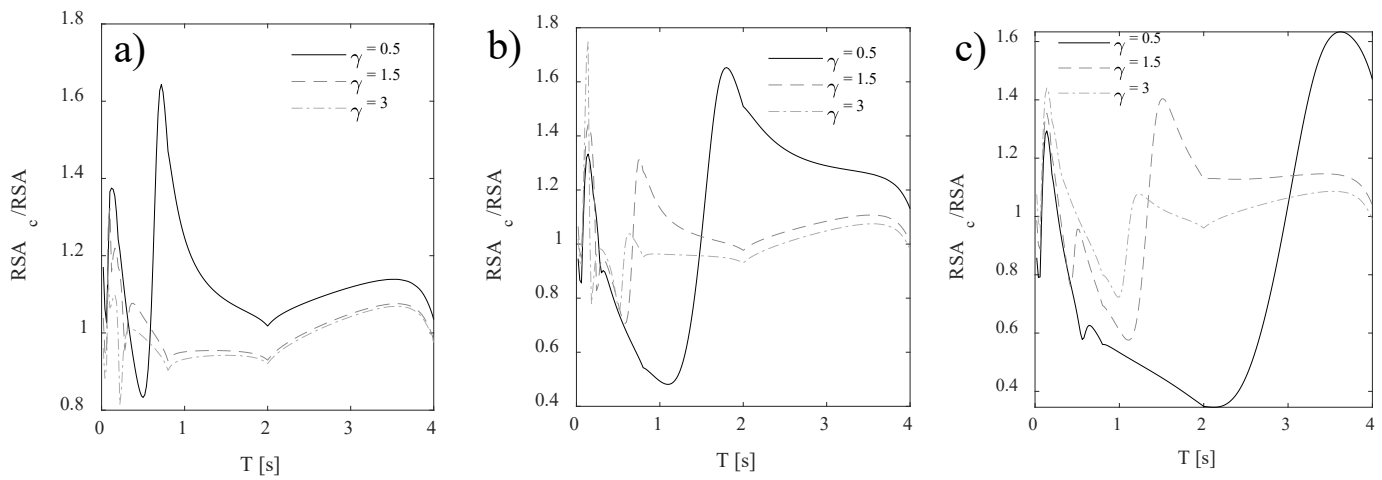

Figure 8 Deviation from the EN1998 response spectrum in acceleration for ground types D induced by a structure with a) $\mathrm{T}_{0}=0.2 \mathrm{~s}$, b) $\mathrm{T}_{0}=0.5 \mathrm{~s}$ and c) a) $\mathrm{T}_{0}=1 \mathrm{~s}$ at a distance $\mathrm{d}=10 \mathrm{~m}$. 

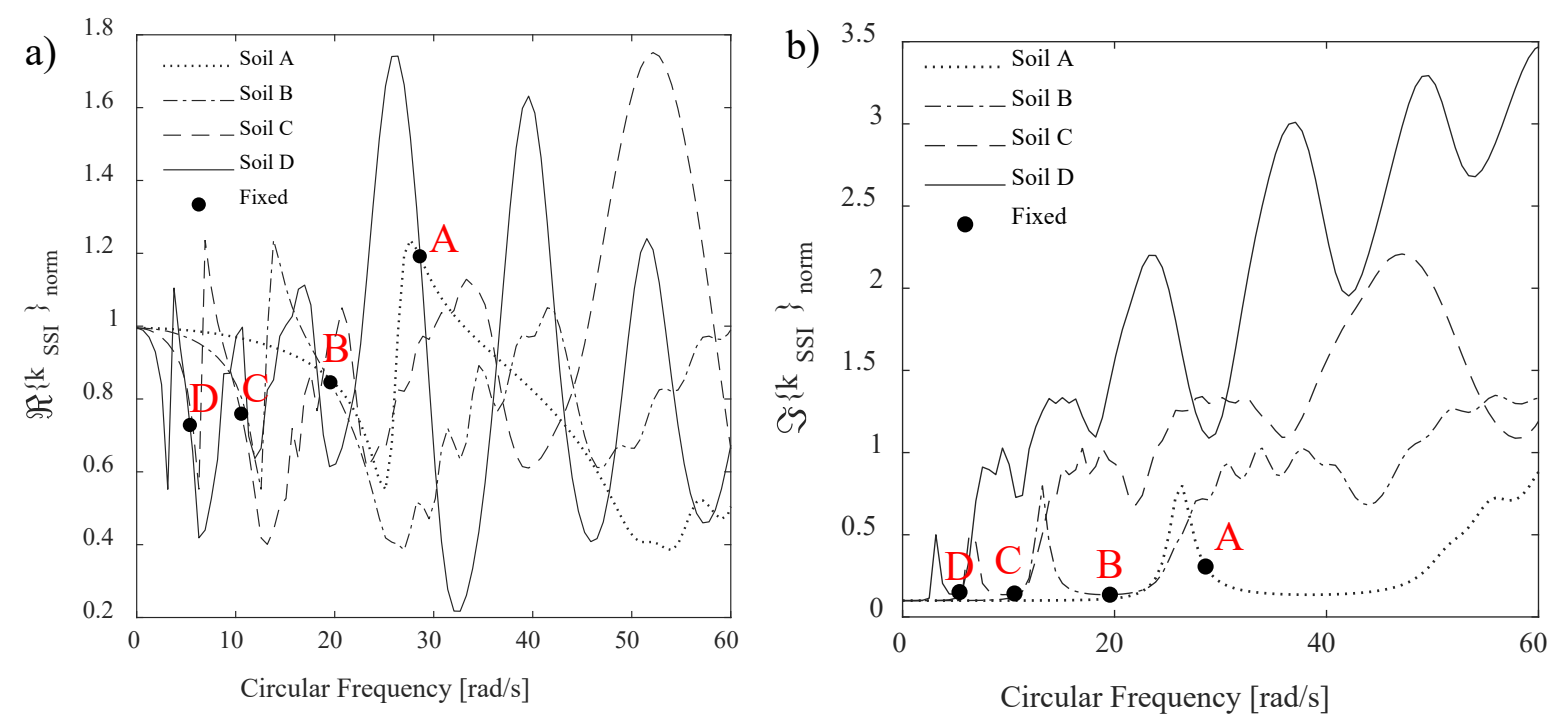

Figure 9 Normalized a) real part and b) imaginary part of the soil-foundation impedances for the examined cases. 


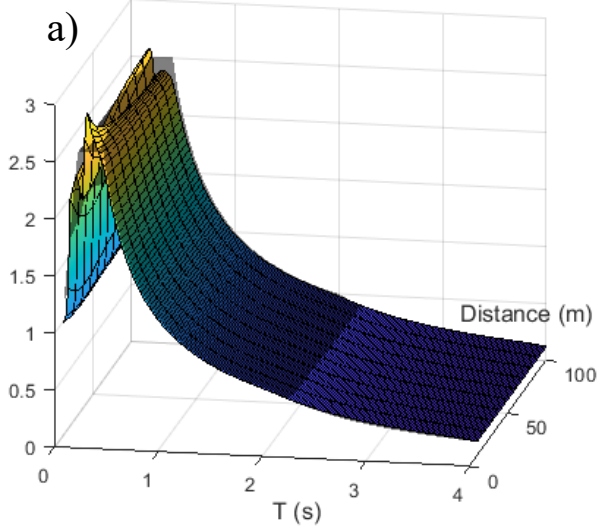

b)

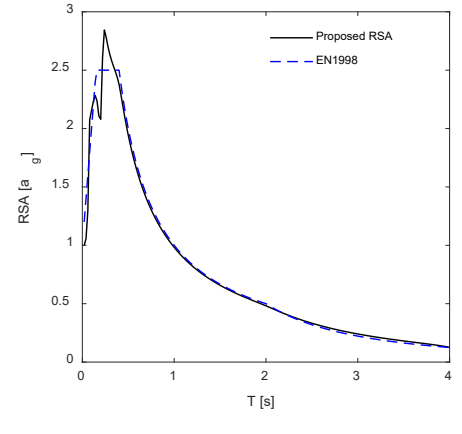

c)

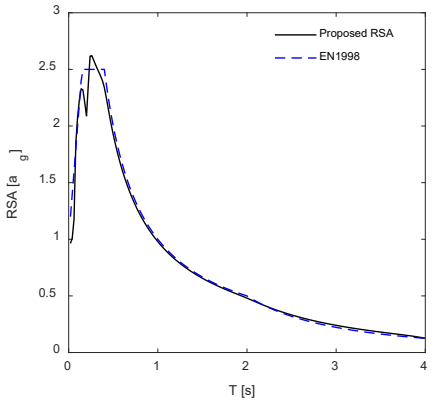

Figure 10 Proposed Response Spectra compatible to ground types A, (a )for varying distances,

(b) $\mathrm{d}=10 \mathrm{~m}$ and (c) $\mathrm{d}=20 \mathrm{~m}$. 

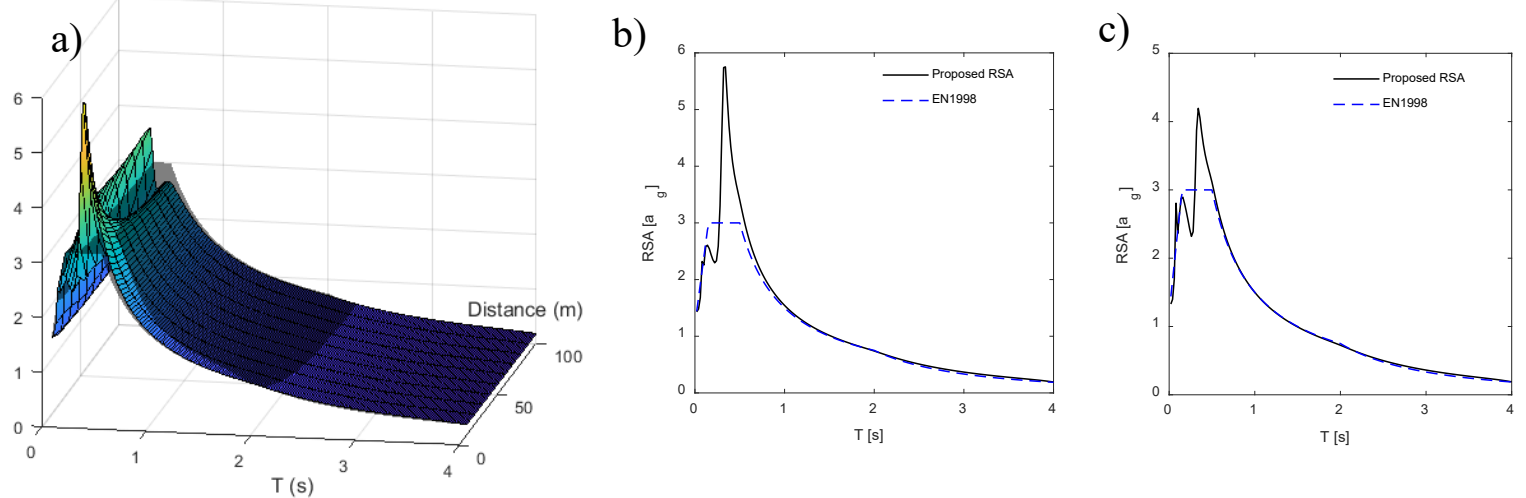

Figure 11 Proposed Response Spectra compatible to ground types B, (a) for varying distances,

(b) $d=10 \mathrm{~m}$ and (c) $\mathrm{d}=20 \mathrm{~m}$ 

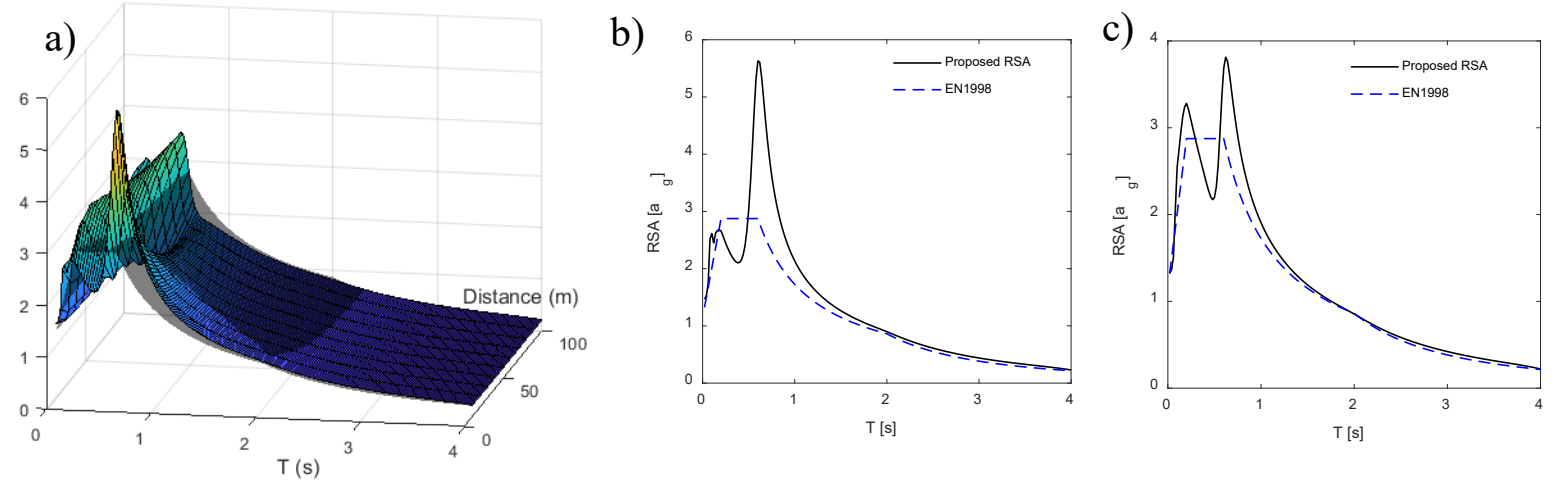

Figure 12 Proposed Response Spectra compatible to ground types C, (a )for varying distances, (b) $\mathrm{d}=10 \mathrm{~m}$ and (c) $\mathrm{d}=20 \mathrm{~m}$. 
a)

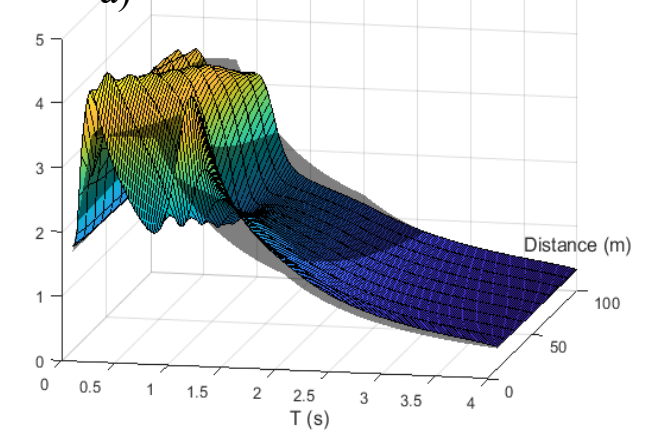

b)

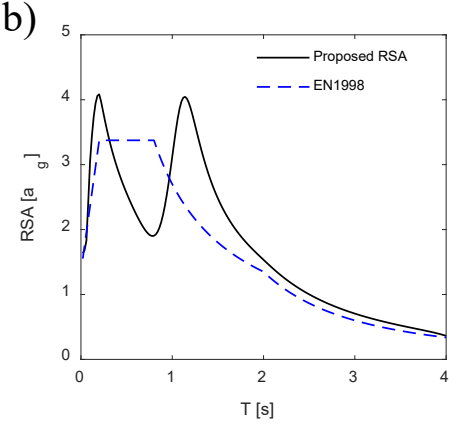

c)

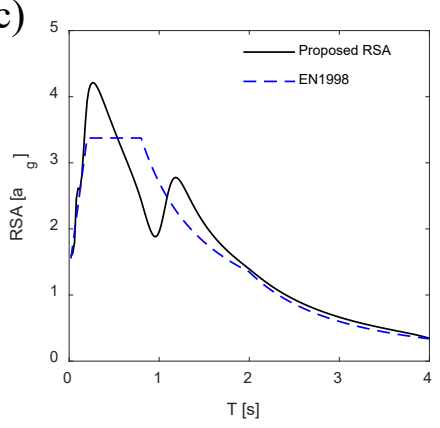

Figure 13 Proposed Response Spectra compatible to ground types D, (a )for varying distances, (b) $\mathrm{d}=10 \mathrm{~m}$ and (c) $\mathrm{d}=20 \mathrm{~m}$. 


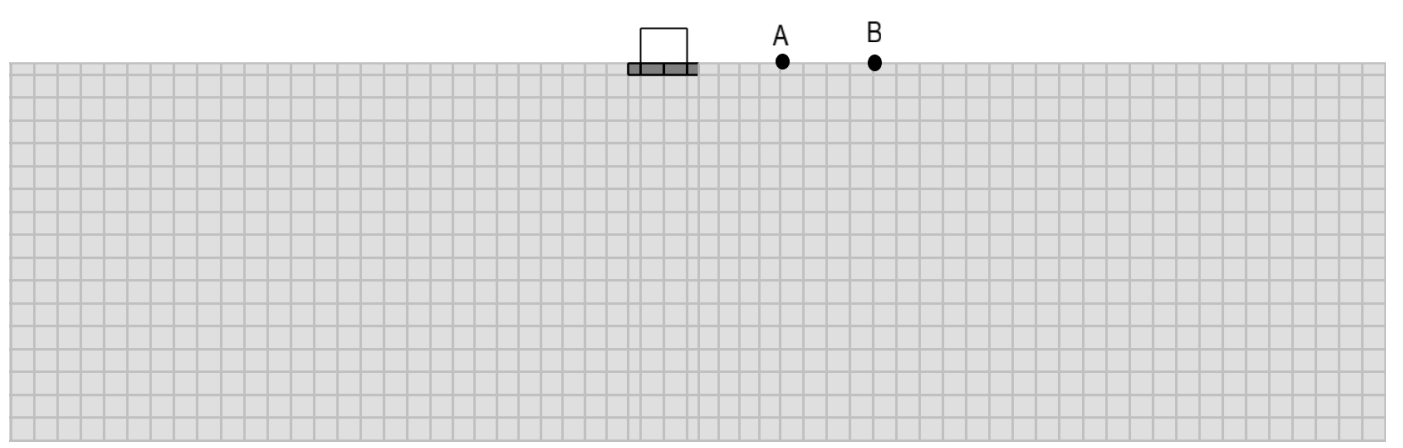

Figure 14 Close up sketch of the finite element model used to calculate the response spectrum in urban environment at two distances $A(d=10 \mathrm{~m})$ and $B(d=20 m)$. 

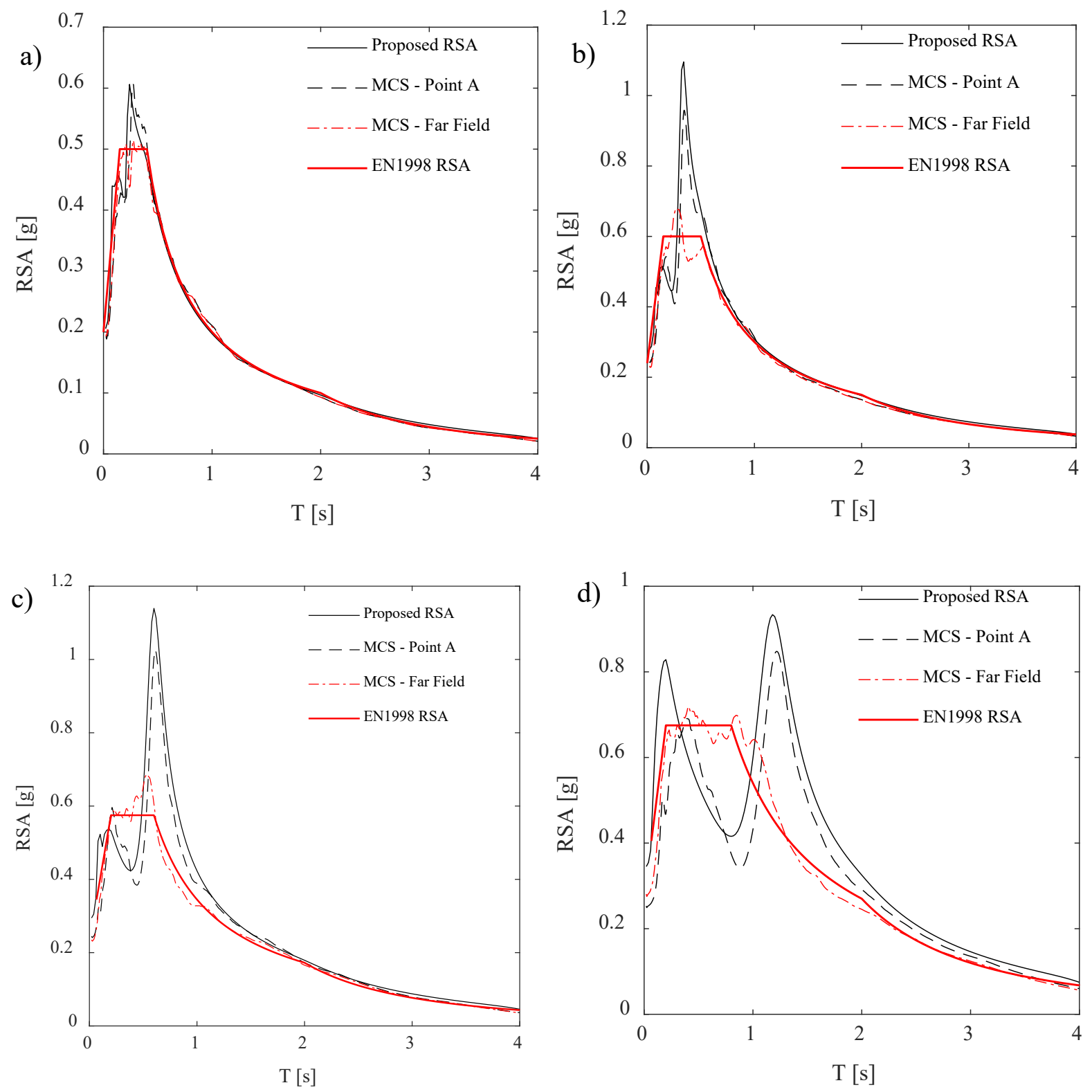

Figure 15 Proposed response spectra for ground types a)A, b)B, c)C, and d)D at the Point A. 

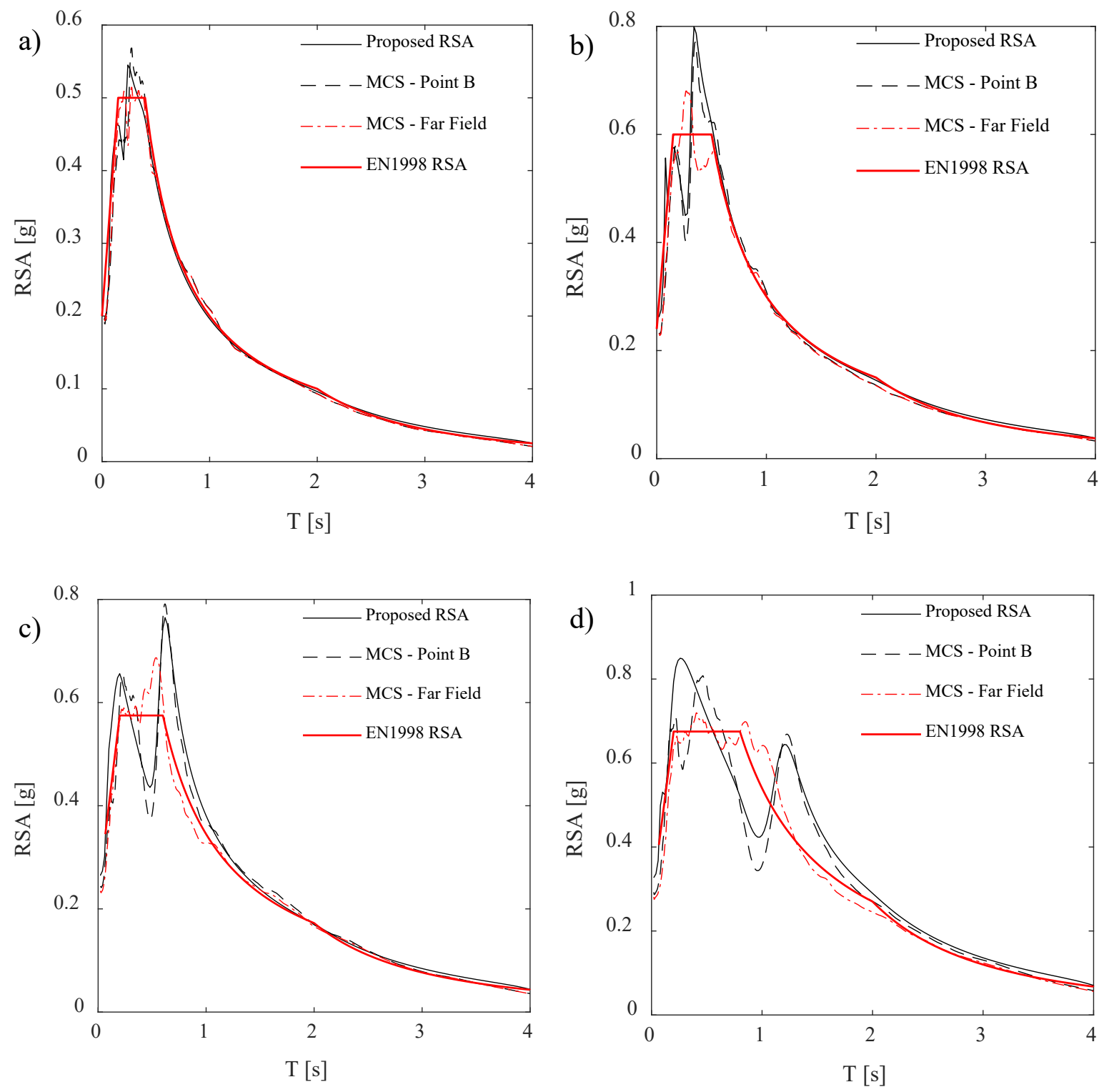

Figure 16 Proposed response spectra for ground types a)A, b)B, c)C, and d)D at the Point B. 

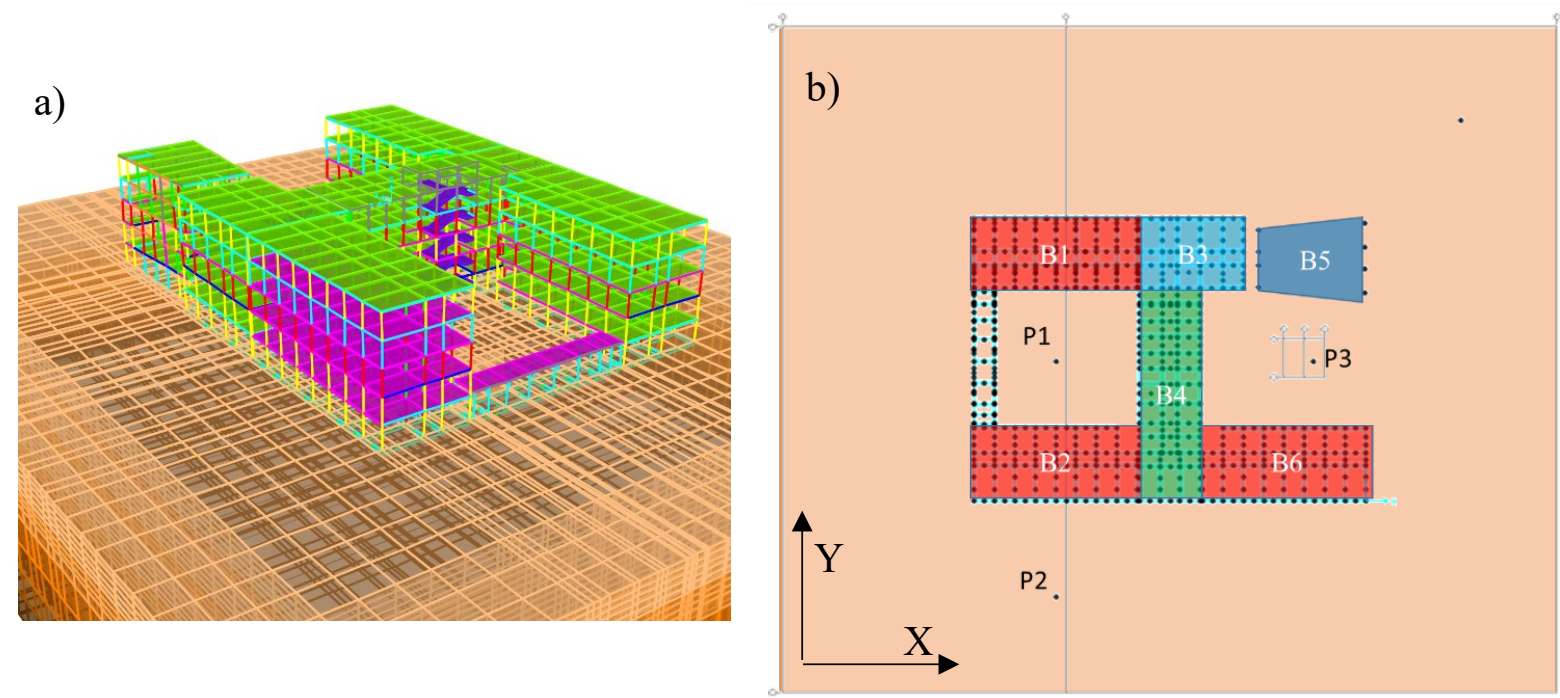

Figure 17 Cluster of buildings a) 3D view and b) position of the buildings related to considered point $\mathrm{P} 1, \mathrm{P} 2$ and $\mathrm{P} 3$. 

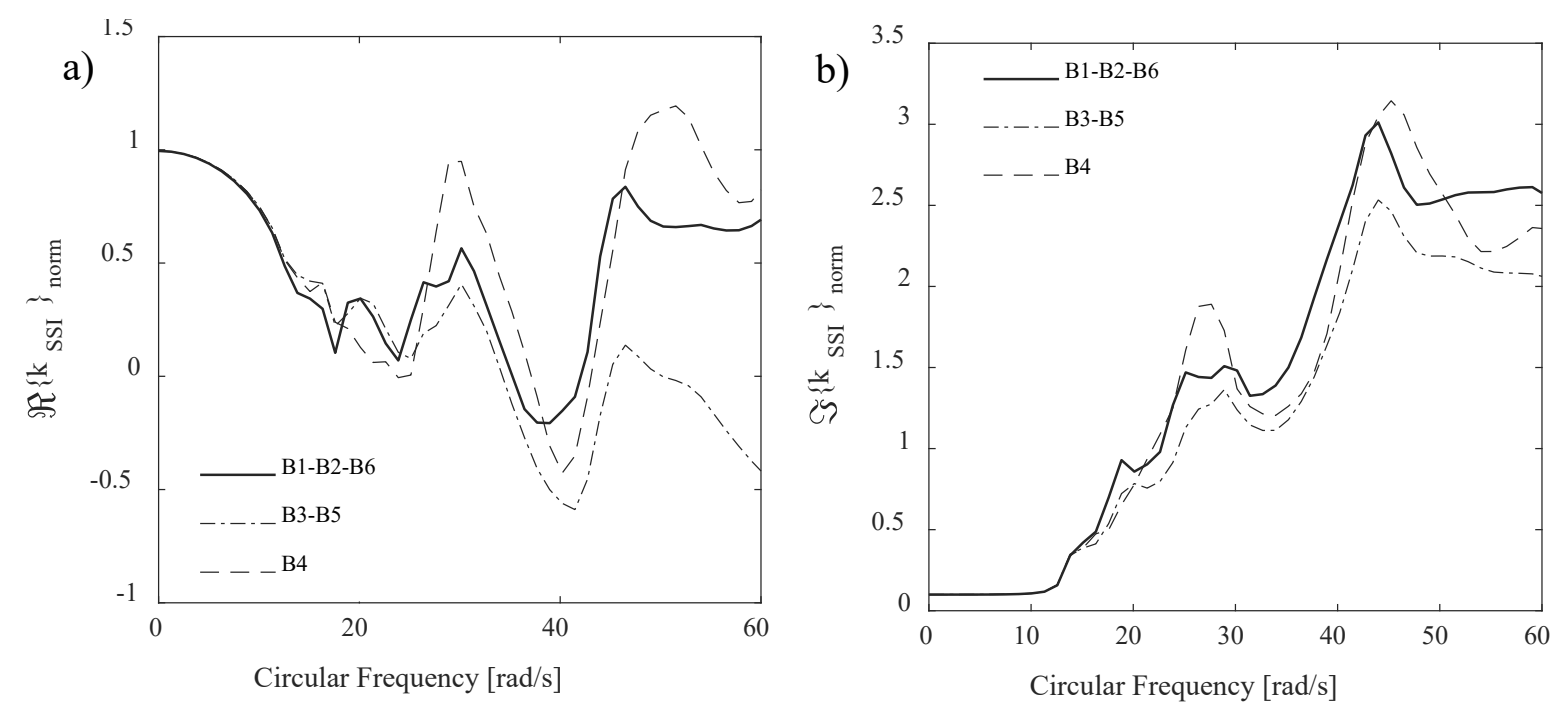

Figure 18 Normalized a) real part and b) imaginary part of the soil-foundation impedances for the examined cases. 

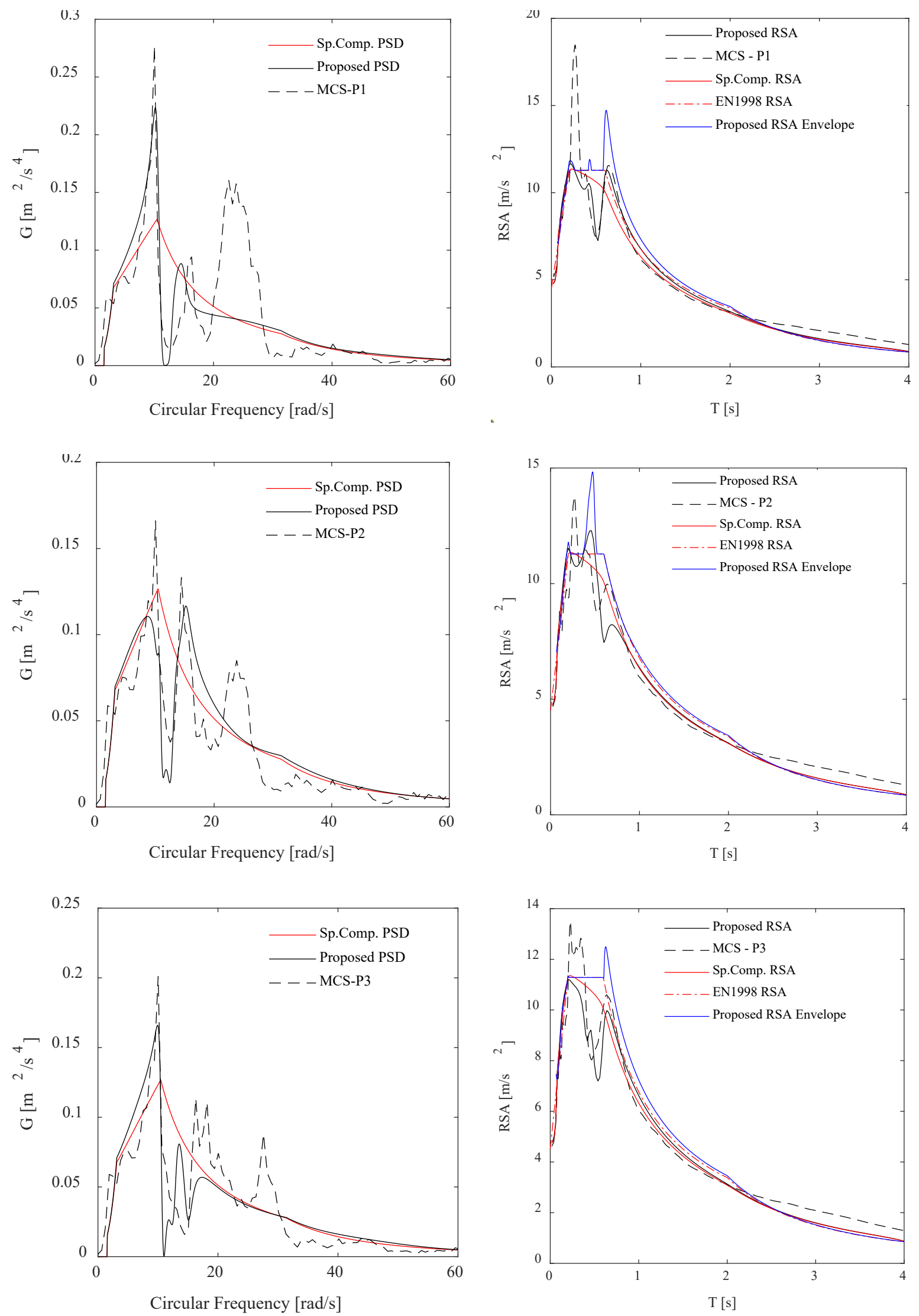

Figure 19 Power Spectral Density functions and Response spectra of the ground motion modified by the cluster of buildings at the selected points P1, P2, P3. 

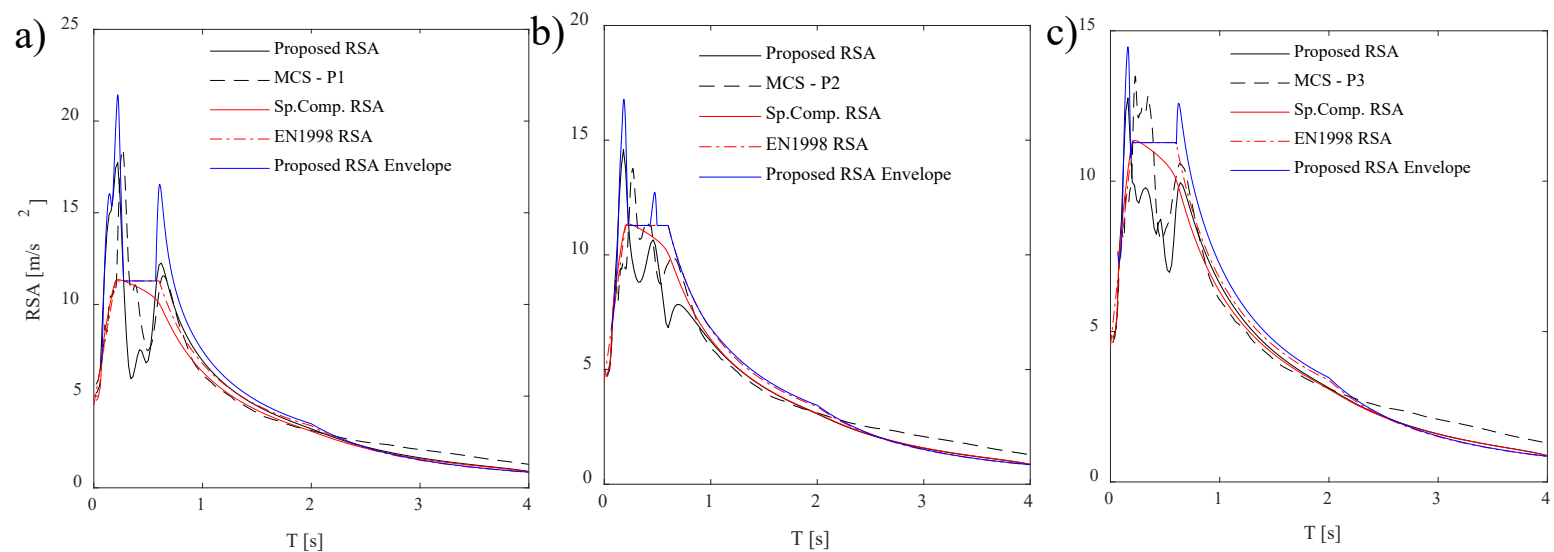

Figure 20 Response spectra considering higher modes of the cluster of buildings at the locations a) P1, b) P2, and c) P3. 